$$
\begin{gathered}
\text { UNIVERSIDADE DE SÃO PAULO } \\
\text { HOSPITAL DE REABILITAÇÃO DE ANOMALIAS CRANIOFACIAIS }
\end{gathered}
$$

VIVIANE MENDES FERNANDES

CORTISOL SALIVAR E ATENÇÃO AUDITIVA SUSTENTADA 

VIVIANE MENDES FERNANDES

\section{CORTISOL SALIVAR E ATENÇÃO AUDITIVA SUSTENTADA}

Tese apresentada ao Hospital de Reabilitação de Anomalias Craniofaciais da Universidade de São Paulo, para a obtenção do título de DOUTORA em Ciências da Reabilitação.

Área de concentração: Fissuras Orofaciais e Anomalias Relacionadas

Orientadora: Prof. ${ }^{\underline{a}}$ Dr. ${ }^{\underline{a}}$ Mariza Ribeiro Feniman

Co-orientadora: Prof. ${ }^{a}$ Dr. ${ }^{a}$ Márcia Ribeiro Gomide 


\section{UNIVERSIDADE DE SÃO PAULO \\ HOSPITAL DE REABILITAÇÃO DE ANOMALIAS CRANIOFACIAIS}

Rua Silvio Marchione, 3-20.

Caixa postal: 1501

17012-900 Bauru/SP - Brasil

(14) $3235-8000$

Prof. Dr. Marco Antonio Zago - Reitor da USP

Dra. Maria Aparecida de Andrade Moreira Machado - Superintendente do HRAC-USP

Autorizo, exclusivamente, para fins acadêmicos e científicos, a reprodução total ou parcial deste trabalho.

Viviane Mendes Fernandes

Bauru, de de

Fernandes, Viviane Mendes

F391c Cortisol salivar e atenção auditiva sustentada / Viviane Mendes Fernandes. Bauru, 2017. $127 \mathrm{f} .: \mathrm{il} ; 31 \mathrm{~cm}$

Tese (Doutorado em Ciências da Reabilitação) - HRAC/USP

Cópia revisada em

Orientadora: Mariza Ribeiro Feniman

1. Cortisol. 2. Saliva. 3. Criança. 4. Atenção. 
FOLHA DE APROVAÇÃO

Dissertação apresentada e defendida por Viviane Mendes Fernandes e aprovada pela Comissão Julgadora em

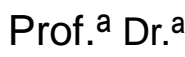

Prof. ${ }^{\text {a }}$ Dr. ${ }^{\text {a }}$

Prof. ${ }^{\text {D }}$..$\underline{a}$

Prof. Dr.. a $\quad$ Mariza Ribeiro Feniman

Hospital de Reabilitação de Anomalias Craniofaciais /USP (Orientadora)

Prof. ․ Dr. ‥ Daniela Gamba Garib

Presidente da Comissão de Pós-Graduação do HRAC/USP

Data de depósito da dissertação junto à SPG 

VIVIANE MENDES FERNANDES

14 de junho de $1983 \quad$ Nascimento

Bauru/SP

2000-2006

Curso de Odontologia - Faculdade de Odontologia de Bauru - Universidade do Sagrado Coração.

2007-2008

Curso de Especialização em Odontopediatria, na Faculdade de Odontologia da Universidade Federal de Santa Catarina.

2010-2013

Curso de Pós-Graduação em Ciências da Reabilitação com qualificação em Fissuras Orofaciais e Anomalias Relacionadas, em nível de Mestrado, no Hospital de Reabilitação de Anomalias Craniofaciais/USP. 

1 edico este trabalho...

Alos meus pais, Soño e charly Alos meus irmãos, 円anessa @inicius

Alo meu sobrinho, chateus, meu bolo fofo, sinônimo de alegria e amor

Qsou eternamente grata por formar uma familia com vocês! 



\section{AGRADECIMENTOS}

A Deus e a Nossa SENHORA,

por guiarem meus passos e sempre prepararem o melhor pra mim. Esta fase do Doutorado foi mais uma prova de que Deus nunca nos deixa sem amparo e que sempre Quer o melhor, mesmo que isso não fique claro em um primeiro momento.

\section{À Prof. a Dr. - MARIZA RIBEIRO FENIMAN,}

que sempre esteve disposta a compartilhar seus conhecimentos e não poupou esforços para me orientar durante estes três anos, mesmo não sendo da mesma área de formação. Obrigada por todo o exemplo de humildade e profissionalismo.

\section{À Prof. 믐. DARCIA RIBEIRO GOMIDE,}

que já em um primeiro pedido, me "adotou" sem hesitar. Muito obrigada por sua compaixão e por todo o carinho desde 2010, quando cheguei para fazer o Mestrado.

Aos meus pais, JOÃo e MARLY,

muito obrigada por serem meu porto seguro e me darem a certeza que sempre poderei contar com vocês para tudo que precisar. Obrigada por serem meus exemplos preferidos de pais, educadores e de amigo verdadeiro.

Aos meus irmãos, VANESSA e VINICIUS,

obrigada pela linda amizade e amorosidade que temos e pela ajuda na parte artística desta Tese.

Ao meu fofíssimo sobrinho, MATEUS,

você ainda é muito pequeno para entender, mas que fique registrado que desde que nasceu, já chegou para abalar todas as estruturas. Com você, minha vida é muito mais alegre e leve. Impossível esquecer as várias vezes em 

que você foi até o computador e "digitou" muitas coisas no meio desta Tese. Amo você.

Ao meu querido cunhado DANILO,

obrigada por todas as conversas e por toda a parceria. Você é um presente para nossa família.

À minha querida e sábia amiga, CLAUDIA, obrigada pela companhia e por todas as conversas.

À minha querida "amiga-irmã" LIGIA, nem tenho palavras para agradecer tudo o que você fez e sempre faz por mim. Obrigada por não medir esforços nos momentos mais tensos desta fase. Agradeço pelos conselhos e todas as broncas também!

Às fonoaudiólogas MARIA RENATA e GABRIELA, pela ajuda, paciência, incentivo constante e total entrega durante a confecção desta Tese. Vocês foram vitais para o desenvolvimento desta pesquisa. Sem vocês nada seria possível. E também à ALINE e BRUNA, por todo o auxílio durante a fase de coleta.

Às queridas amigas PAULINHA e MAíRA, que mesmo de longe, se fazem presentes diariamente, sempre prestativas. Obrigada pela ajuda com o inglês, pelo ombro, colo e ouvidos quando precisei.

À amiga e afilhada, MARIANA JALES,

por sua constante amizade, alegria e auxílio nas minha dúvidas em audiologia. Obrigada por se mostrar sempre disposta a ajudar.

Ao Thiago Dionísıo, que realizou a parte laboratorial da pesquisa. Obrigada pela disponibilidade e por não medir esforços para me ajudar, sempre que precisei. 

À Prof. ${ }^{a}$ Dr.. a Cleide Felício de Carvalho CaRRara, exemplo de humildade e generosidade. Obrigada por se mostrar disposta a atender qualquer pedido ou ajuda solicitada. O seu esforço em espalhar por aí todo seu conhecimento, sem querer guardar só para si, é encantador.

Às professoras BIA e GISELE,

exemplos de dedicação e amor às crianças do Centrinho. Obrigada pela orientação nos artigos paralelos à tese.

Ao querido Prof. Dr. Manoel Henrique Salgado,

que realizou toda a estatística deste trabalho com enorme dedicação e entrega.

\section{À CAPES,}

por todo apoio financeiro durante o Doutorado, viabilizando a realização desta pesquisa.

A todos os pacientes, pais e responsáveis, que tornaram possível a realização desta pesquisa, toda a minha gratidão. 

Tudo o que acontece de ruim, é pra melhorar. Daulinho CKoska 



\section{LISTA DE FIGURAS}

Figura 1 - Exemplos fornecidos pelo fabricante de níveis esperados de cortisol salivar, nas diferentes idade 



\section{LISTA DE TABELAS}

Tabela 1 - Distribuição das crianças segundo a idade, sexo e tipo de fissura labiopalatina

Tabela 2 - Média do cortisol salivar, segundo a idade 81

Tabela 3 - Média do cortisol salivar, segundo o sexo e idade 81

Tabela 4 - Valores encontrados de cortisol, segundo o número de atendimento

Tabela 5- Coeficiente de correlação entre o número de atendimentos pelos quais a criança passou e o nível de cortisol

Tabela 6 - Valores médios e desvio-padrão(DP) do THAAS por idade 83

Tabela 7 - Valores médios dos erros (desatenção, impulsividade e pontuação total) e decréscimo de vigilância nas faixas etárias segundo os sexos 83

Tabela 8 - Coeficiente de correlação entre os sexos no desempenho no THAAS 83

Tabela 9 - Coeficiente de correlação entre o desempenho no THAAS e o nível de cortisol 



\section{RESUMO}

FERNANDES, VM. Cortisol salivar e atenção auditiva sustentada [tese]. Bauru: Hospital de Reabilitação de Anomalias Craniofaciais, Universidade de São Paulo, 2017.

Objetivo: Verificar uma possível correlação entre o nível de cortisol salivar e a atenção auditiva sustentada em crianças com fissura labiopalatina.

Local de Execução: Hospital de Reabilitação de Anomalias Craniofaciais.

Método: Estudo prospectivo com 69 crianças de seis a 11 anos de idade, com fissura labiopalatina, com audição normal e sem histórico de desatenção. As crianças foram submetidas à coleta de saliva, para a mensuração do nível de cortisol, e ao Teste de Habilidade de Atenção Auditiva Sustentada (THAAS), para verificar a atenção sustentada.

Resultados: Os resultados demonstraram a ausência de significância estatística entre os sexos, tanto para o nível de cortisol quanto para a atenção auditiva sustentada. As crianças de 7 anos apresentaram os piores resultados na atenção sustentada e os mais altos níveis de cortisol salivar.

Conclusão: Foi possível verificar correlação positiva, com diferença estatisticamente significativa, entre o nível de cortisol salivar e a habilidade de atenção auditiva sustentada apenas nas crianças com fissura labiopalatina na faixa etária de sete anos.

Descritores: cortisol, saliva, criança, atenção. 



\section{SUMMARY}

FERNANDES, VM. Salivary cortisol and sustained auditory attention [these]. Bauru: Hospital de Reabilitação de Anomalias Craniofaciais, Universidade de São Paulo, 2017.

Objective: To verify a possible correlation between salivary cortisol level and sustained auditory attention in children with cleft lip and palate.

Place of Execution: Hospital of Rehabilitation of Craniofacial Anomalies.

Method: Prospective study with 69 children from 6 to 11 years of age, with cleft lip and palate, with normal hearing and no history of inattention. The children were submitted to saliva collection for the measurement of cortisol level and to the Sustained Auditory Attention Ability Test (SAAAT) to verify sustained attention.

Results: The results demonstrated the absence of statistical significance between the sexes, both for the cortisol level and for the sustained auditory attention. The 7-year-old children had the worst results in sustained attention and the highest levels of salivary cortisol.

Conclusion: A positive correlation with a statistically significant difference between salivary cortisol level and sustained auditory attention ability was observed only in children with cleft lip and palate at the age of seven years.

Keywords: cortisol, saliva, children, attention. 



\section{SUMÁRIO}

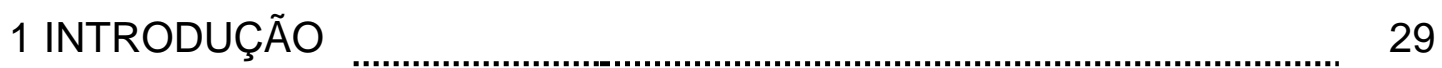

2 REVISÃO DE LITERATURA _............................................................... 35

2.1 Fissura e reabilitação ..................................................................... 35

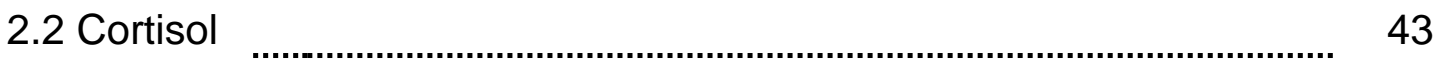

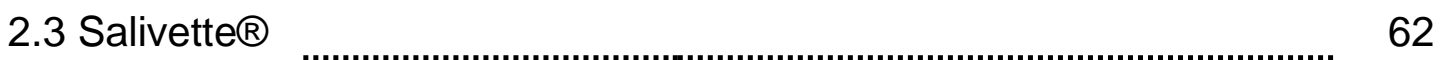

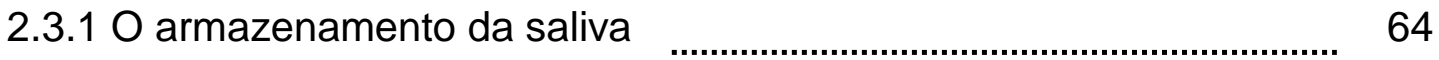

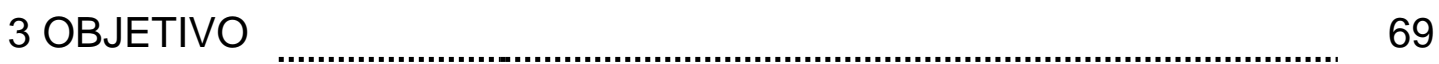

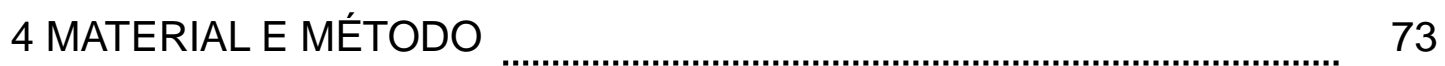

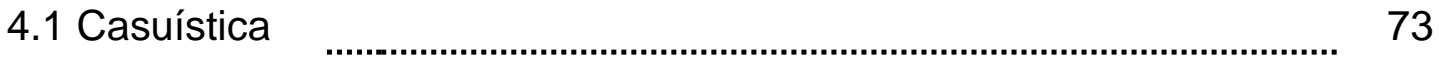

4.2 Procedimentos _.......................................................................... 75

4.2.1 Coleta de saliva .................................................................... $\quad 75$

4.2.2 Teste de Habilidade de Atenção Auditiva (THAAS) _........................ 77

4.2.3 Análise estatística ........................................................................... 78

5 RESULTADOS _........................................................................... 81

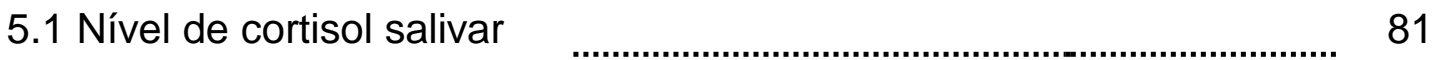

5.2 Teste de Habilidade de Atenção Auditiva Sustentada ………............. 82

6 DISCUSSÃO 87

6.1 Cortisol salivar ............................................................................. 87

6.2 Teste de Habilidade de Atenção Auditiva Sustentada _........................ 91

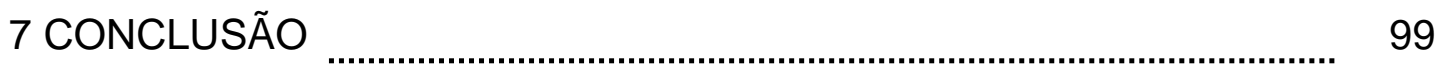

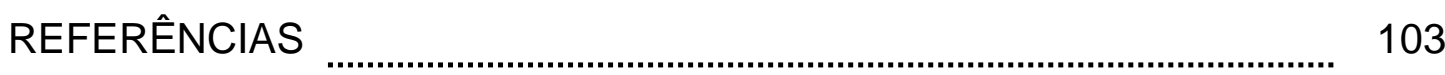

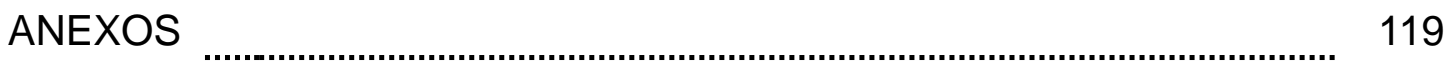

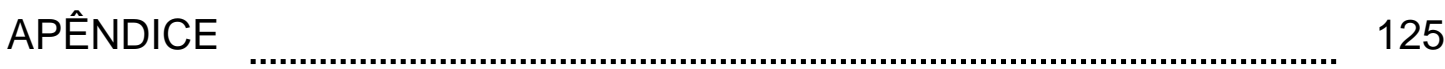



1 बntrodugão 



\section{INTRODUÇÃo}

Situações estressantes, episódios descritos por muitos como banais ou insignificantes, situações de perigos, medo, dor, desafios, ameaças, dependendo das características próprias de personalidade, de experiências anteriores, grau de maturidade, idade do sujeito e ambiente, causam uma grande variedade de respostas adaptativas no cérebro, bem como em outros sistemas do corpo humano. Assim, a atenção é uma função que também pode sofrer variações, em decorrência da exposição a situações estressantes.

A atenção é uma função crucial, que permite a intervenção eficaz do sujeito com seu ambiente, além de auxiliar a organização dos processos mentais. As situações de estresse podem fazer com que o cortisol seja produzido em maiores quantidades do que o habitual, aumentando de 20 a 30 vezes após o estímulo estressor, afetando fortemente a conectividade emocional, visual e cognitiva de maneiras opostas às que deveriam responder; podendo ocorrer decréscimo no nível de atenção e dificuldade na informação verbal. Alguns trabalhos que estudam a relação dos efeitos do estresse e os altos níveis de cortisol relatam sempre efeitos negativos em alguns quesitos como humor, irritação e atenção. A desatenção é um problema que faz com que as pessoas não registrem as informações em suas memórias e, por isso, gastam mais tempo nas tarefas cotidianas, tentando recuperar qual informação foi perdida.

O cortisol é um corticosteroide presente nos fluidos corporais e é produzido pelo córtex adrenal, que é parte da glândula adrenal. É controlado pelo eixo Hipotálamo-Hipófise-Adrenal (HHA) que, em condições de equilíbrio, mantém o ritmo circadiano e é ativado em situações de estresse. Em resposta ao estímulo estressor interno ou externo, inicia-se a secreção da corticotrofina no hipotálamo, o qual provoca a libertação do hormônio adrenocorticotrófico, pela hipófise. O hormônio adrenocorticotrófico, finalmente, provoca a secreção do cortisol, o glucocorticoide, pelo córtex adrenal. O cortisol entra no cérebro em quantidades significativas e provoca uma vasta gama de efeitos específicos de tecidos. 
Em condições basais, o cortisol mostra um ritmo circadiano, com menor secreção durante a primeira metade do sono noturno (chamado período de repouso), com uma elevação durante a segunda metade do sono. Os níveis máximos são atingidos logo após o despertar. Durante o resto do dia, níveis decrescentes são observados continuamente, exceto para surtos de cortisol relacionados ao estresse, que se sobrepõem sobre o ritmo circadiano normal.

O cortisol aumenta a pressão arterial e o açúcar no sangue; também, reduz a resposta imune. A mensuração do cortisol salivar pode fornecer informações importantes sobre o funcionamento do eixo HHA, sob condições normais e de estresse, assim como o envolvimento do cortisol nos mecanismos que determinam a atividade e a adaptação às mudanças ambientais.

A coleta de saliva para análise do nível de cortisol é considerada segura, pois permite uma medida precisa do cortisol que circula livre no sangue. É considerada uma técnica simples, pois necessita de pequena quantidade de saliva para realização da análise laboratorial, não é invasiva e tem baixo custo; além disso, tem dupla vantagem em relação à amostra de sangue, por permitir a coleta sem o uso de agulha, o que poderia gerar um estresse adicional e interferir nos resultados - uma questão particularmente relevante nas pesquisas com crianças. Também, facilita a realização da coleta no domicílio do participante, aspecto que pode aumentar as taxas de participação em estudos.

Pacientes com fissura labiopalatina necessitam de um longo processo reabilitador, iniciado logo nos primeiros meses de vida e que se segue até a idade adulta. Pode-se supor que perturbação da estrutura normal facial e a necessidade do tratamento em centros especializados, nos quais os pacientes são internados e passam por longos períodos longe do lar, como ocorre no Hospital de Reabilitação de Anomalias Craniofaciais, da Universidade de São Paulo (HRAC), podem gerar um grande estresse ao paciente, especialmente na primeira infância, quando o medo do desconhecido é um fator muito marcante. 
Sabendo-se que: pacientes com fissura labiopalatina em tratamento em centros especializados estão submetidos, com grande frequência, a procedimentos da área da saúde, ocasionados pelos frequentes retornos para continuidade do tratamento; que os níveis de cortisol podem ser elevados pelo estresse; e, que a atenção auditiva sustentada pode se alterar sob estresse, esta pesquisa tem como objetivo verificar junto a pacientes do HRAC, durante um dia de rotina hospitalar, se existe correlação entre os níveis de cortisol salivar e o número de atendimentos realizados no dia, bem como entre os níveis de cortisol e a atenção auditiva sustentada. 

2 Qevisão de Riteratura 



\section{REVISÃo dE LITERATURA}

\subsection{Fissura e reabilitação}

Entre as malformações congênitas, as fissuras labiopalatinas são as mais prevalentes no ser humano e são reconhecidas pela Organização Mundial de Saúde, assim como a desnutrição e as doenças infecciosas, como um dos problemas de saúde pública mais relevante. No mundo, nasce uma criança com fissura a cada dois minutos e meio e, no Brasil, registram-se 5.800 nascimentos por ano (WHO 2002). Em estudos epidemiológicos realizados no mundo, a prevalência de fissuras labiopalatinas varia de acordo com os países: somente $1,07 \%$ no Japão e 4,3\% em Taiwan. No Brasil, a prevalência varia de 0,47 e 1,54 a cada 1.000 nascidos vivos (Cymrot et al. 2010).

As fissuras labiopalatinas são alterações faciais de origem embriológicas, em razão da falta de fusão dos processos nasais mediais entre si e destes com os processos maxilares (lateralmente). Devido às alterações anatômicas e funcionais, os pacientes com fissura apresentam diversas alterações relacionadas às áreas médica, odontológica e fonoaudiológica (Melgaço et al. 2002). De acordo com Silva Filho e Freitas (2007), as fissuras labiopalatinas podem envolver os lábios, o rebordo alveolar e o palato e envolvem fatores genéticos e ambientais.

$\mathrm{Na}$ atualidade, as fissuras labiopalatinas podem ser diagnosticadas até mesmo na vida pré-natal (Garib et al. 2010) e, como todo diagnóstico precoce, isso faz ampliar as possibilidades de antecipar medidas corretivas, que beneficiarão o paciente não somente no aspecto estético, como psicológico e emocional. A reabilitação do paciente com fissura labiopalatal, portanto, tem como objetivo não só capacitar para sua integração na sociedade, mas propiciar sua inclusão social. A reabilitação envolve a ação de uma equipe interdisciplinar, numa relação de reciprocidade, mutualidade e diálogo. Nessa relação, a colaboração entre as diversas áreas é fundamental (Trindade e Silva Filho 2007).

Desta forma, a qualidade do tratamento aos pacientes requer 
avaliações dos resultados dos tratamentos realizados, revisão periódica dos dados da evolução clínica e adaptação da equipe de tratamento, quando as avaliações de resultados clínicos não atingem os critérios referenciados (Semb et al. 2005, Darvann et al. 2007, Noordhoff 2009, Reddy et al. 2009, Vargervik et al. 2009, Wang et al. 2009).

Para Gassling et al. (2012), o conceito de tratamento de fissuras labiopalatais requer cuidados multidisciplinares, incluindo maxilofacial, cirurgia, ortodontia, otorrinolaringologia, fonoaudiologia e odontologia. Para esses autores, os avanços na área da cirurgia plástica, proporcionam um tratamento satisfatório, especialmente nas últimas décadas, no entanto, questionam se o tratamento médico é suficiente ou se precisa se concentrar em outros aspectos, que têm sido negligenciados nesse tipo de malformação, referindo-se especialmente ao estresse resultante das pressões sociais a que ficam submetidos os indivíduos com fissura labiopalatal.

Para Angerami (2004), o impacto da criança internada no hospital é grande, pois elas têm dificuldades para assimilar a situação, apresentando medo, angústia e ansiedade, fantasias causadas pela falta de informação adequada, falta de prognóstico ou de tratamento.

Segundo Chaves (2004), diante da hospitalização, a criança pode apresentar sentimentos como medo, sensação de abandono, sensação de punição, que podem desencadear mais sofrimento e dificuldade de intervenção para a equipe. Tudo isso ocorre ao mesmo tempo, mas com intensidades diferentes em cada criança, dependendo da idade, situação psicológica afetiva, rotinas hospitalares, motivo e duração da internação.

\subsection{Atenção auditiva sustentada}

A atenção está presente no dia a dia, possibilitando selecionar quais estímulos são importantes para realização de tarefas (Mondelli et al. 2010). Os circuitos cerebrais, que regulam 0 foco da atenção, iniciam seu desenvolvimento durante a infância, período em que as crianças vão 
adquirindo, gradualmente, a capacidade de direcionar a atenção até os níveis encontrados nos adultos. Nos idosos, observa-se uma diminuição dessa habilidade, devido à dificuldade de inibir estímulos competitivos (Cosenza e Guerra 2011). A atenção caracteriza-se pela sua seletividade e intensidade. A seletividade estreita o foco do processamento da informação e a intensidade melhora a qualidade do processamento, uma vez que o foco é reduzido (Richards 2004). A atenção sustentada é a detenção de uma determinada informação durante um período de tempo. A vigilância é a habilidade de manter-se preparado para responder a algum sinal de ameaça (Klorman et al. 1991). Fatores estressores podem representar desafios para a atenção cognitiva ou não-cognitiva (Jacobson 2005)

A desatenção é um problema que faz com que a pessoa perca as informações em sua memória de trabalho, e, por isso, perdem tempo tentando recuperar qual informação foi perdida e, como resultado, o processamento da informação é atrasado (Feniman et al. 2007a).

Greenberg e Waldman (1993) realizaram uma pesquisa para apresentar dados normativos para o "Test of Variables of Attention" (TOVA). O teste tem exigências mínimas de linguagem e não requer discriminação de esquerda e direita. Os autores relataram que essas características são significativas, uma vez que as crianças que demonstram problemas com atenção e impulsividade, frequentemente, demonstram problemas de aprendizagem, os quais podem incluir dificuldade com linguagem e com discriminação de direita e esquerda. Para eles, a avaliação da desatenção e da impulsividade com o TOVA pode ser livre desses vieses - que podem ocorrer com outros testes realizados com base em estímulos de linguagem ou números ou testes que requerem atenção a uma sequência de estímulos específicos. A casuística foi composta por 775 crianças, com idades entre seis a 16 anos, e o TOVA foi realizado da seguinte forma: a criança ficou posicionada em frente a um computador, o qual tinha um quadrado colorido em sua tela. Outro quadrado, menor, era projetado na tela (dentro do quadrado colorido) durante 100 milissegundos a cada dois segundos. Os sujeitos foram instruídos a pressionar um botão toda vez que vissem o quadrado menor. O teste foi administrado durante uma única sessão, de 23 minutos. Todas as crianças 
foram testadas no mesmo período do dia, para minimizar qualquer variação diurna que pudesse ocorrer nessas tarefas. As pontuações registradas no TOVA incluem: ${ }^{\text {a) }}$ erros de omissão (quando o indivíduo não responde no momento em que o quadrado menor aparece na tela), comumente interpretados como uma medida de desatenção; ${ }^{\text {b) }}$ erros de comissão (quando o indivíduo responde em um momento que o quadrado não apareceu), comumente interpretados impulsividade; e, ${ }^{c)}$ tempo de resposta médio para respostas corretas, que é interpretado como a velocidade de resposta motora. Os resultados desse trabalho mostraram que a porcentagem de erros de omissão foi maior para os meninos do que para as meninas, embora não houvesse diferença significativa entre os sexos. Os meninos também apresentaram mais erros de comissão do que as meninas. $O$ tempo de reação apresentou um decréscimo conforme a idade: as meninas apresentaram um tempo de reação médio mais lento do que os meninos, especialmente nas menores faixas etárias. Os autores concluíram que o TOVA pode servir como uma medida sensível de desatenção e impulsividade, em situações clínicas.

Lin et al (1999) mensuraram a atenção sustentada de 341 crianças de seis a 15 anos, utilizando o "Continuous Performance Test" (CPT), um teste composto de duas fases. Nele, as crianças deveriam apertar um botão quando visualizassem o número nove precedido pelo número um. A diferença entre as fases foi que, na segunda parte, o plano de fundo do computador era alterado para dificultar a visualização e exigir mais da atenção dos participantes. Foram apresentados, no total, 341 estímulos visuais em uma tela de computador, por um período de cinco minutos. O resultado do teste foi calculado pelos acertos (pontuação pelas vezes que criança apertou o botão no momento correto) e erros (pontuação pelas vezes que a criança apertou o botão no momento errado). Os resultados mostraram que tanto para a primeira quanto para a segunda fase do teste, a taxa de acertos aumentou e a taxa de erros diminuiu com a idade. Os autores concluíram que o desempenho das crianças no teste pode possibilitar uma padronização adequada para classificar a criança como "normal" ou com "déficit", no entanto, consideraram que seria importante realizar uma padronização por sexo. 
Feniman (2004), utilizando o Teste de Habilidade da Atenção Auditiva Sustentada (THAAS), verificou o desempenho de crianças com audição periférica normal e sem histórico de déficit de atenção, com o objetivo de avaliar a habilidade da criança em escutar estímulos auditivos durante um período de tempo prolongado e responder somente para o estímulo específico. A autora concluiu que os escores do THAAS estavam relacionados com a idade do sujeito: as crianças menores demonstraram maior número de erros de desatenção e impulsividade do que aquelas com maior idade. Também, a habilidade de sustentar a atenção deteriorou-se com o tempo da tarefa. $\mathrm{Na}$ comparação com estudo semelhante, as crianças brasileiras atingiram escores mais elevados do que as americanas (exceto para a faixa etária de 11 anos), e este instrumento mostrou-se altamente sugestivo para identificação de problemas de atenção auditiva sustentada em crianças.

Miranda et al. (2009) realizaram um trabalho com o objetivo de determinar o desempenho no "Continuous Performance Test" (K-CPT) - um teste utilizado para auxiliar no diagnóstico de distúrbios de atenção, tais como o transtorno do déficit de atenção e hiperatividade (TDAH) - de crianças brasileiras com idades entre quatro e cinco anos e comparar com os dados padronizados de crianças norte-americanas. O teste K-CPT realiza-se em um "laptop", no qual figuras são apresentadas na tela. A criança é instruída a pressionar a tecla "espaço" sempre que uma figura aparecer, exceto se a figura for uma bola. Foi considerado "omissão", quando o sujeito não conseguiu responder, ou seja, quando a resposta não foi dada (sendo omitida) para figuras que não era a bola. Foi considerado "comissão", quando o sujeito respondeu a um estímulo que não era o alvo, ou seja, quando a tecla espaço foi pressionada à figura da bola. Os autores descreveram que um tempo de reação longo combinado com um grande número de erros de omissão e comissão, indicava desatenção, enquanto que um tempo de reação rápido combinado com muitos erros de comissão, mas poucos erros de omissão, refletia impulsividade. $O$ teste teve duração de 7,5 minutos. $O$ estudo mostrou que os meninos tiveram resultados melhores do que as meninas, em relação ao quesito "omissão". Entretanto para o quesito "comissão", as meninas tiveram melhores resultados que os meninos. Em comparação com a 
padronização americana, as crianças brasileiras apresentaram melhores resultados. Os autores concluíram que os dados apresentados podem ser utilizados como um guia para crianças de quatro e cinco anos, tornando viável a identificação de possíveis distúrbios de atenção no Brasil.

A atenção auditiva de escolares pode ser influenciada por alterações auditivas, causando prejuízo nas habilidades de atenção e compreensão e, consequentemente, comprometendo o desempenho e aprendizado escolar destas crianças (Araújo et al. 2002). Com o intuito de verificar o desempenho de crianças diagnosticadas com perda auditiva bilateral de grau leve (condutiva e sensorioneural) no THAAS, Mondelli et al. (2010) aplicaram este instrumento em 90 crianças, na faixa etária entre sete e 11 anos de idade. O G1, grupo controle, foi formado por crianças com audição periférica normal; o G2, integrado por crianças com deficiência auditiva sensorioneural; e, G3, composto por crianças com perda auditiva condutiva. Os resultados desse estudo demonstraram que o desempenho dos grupos G2 e G3 foram inferiores em relação ao grupo controle em todas as respostas do THAAS. Também, em relação ao tipo de deficiência condutiva, nessa amostra foi observado que as crianças com deficiência auditiva sensorioneural (G2) apresentavam maior comprometimento na habilidade de atenção auditiva sustentada que as crianças com perda auditiva condutiva, as quais apresentaram melhores escores nas respostas do teste.

Para investigar a influência da fissura labiopalatina na habilidade de atenção auditiva sustentada em crianças, Lemos e Feniman (2010) utilizaram o THAAS para avaliar 55 crianças, na faixa etária de sete anos. Os participantes da pesquisa foram divididos em dois grupos: G1, composto por 25 crianças sem fissura labiopalatina, e G2, composto por 30 crianças com fissura labiopalatina. Houve diferença estatisticamente significante somente na variável decréscimo de vigilância. Os resultados obtidos nessa amostra permitiram concluir que, no THAAS, as crianças com fissura labiopalatina apresentavam desempenho inferior àquelas sem essa anomalia craniofacial.

Para verificar a influência do período do dia e tipo de escola (particular ou pública) na habilidade de atenção auditiva sustentada em crianças, Picolini et al. (2010) realizaram um estudo com 50 crianças, de 
ambos os gêneros, na faixa etária de sete anos, com audição periférica normal, sem queixas escolares e/ou comportamentais e sem queixas de desatenção. As crianças foram divididas em dois grupos: 25 crianças realizaram o THAAS no período da manhã e o restante no período da tarde. As crianças avaliadas no período da tarde e as que estudam em escolas públicas apresentaram pior desempenho na habilidade de atenção auditiva sustentada, evidenciando que o período do dia e o tipo de escola, tem influência na habilidade da criança em sustentar a atenção auditiva.

Com o objetivo de verificar a possibilidade de realizar o THAAS em campo livre, Feniman et al. (2012) aplicaram o THAAS de duas formas: utilizando fones auriculares e em campo livre. Comparação foi realizada entre elas. O estudo avaliou 40 crianças de sete anos de idade, com desenvolvimento típico dessa faixa etária. Elas foram divididas em dois grupos: G1 e G2, compostos por 20 crianças cada grupo. A aplicação do THAAS no G1 se deu, primeiramente, com fones auriculares e, em seguida, em campo livre; e, no G2, o processo foi realizado de forma inversa. De acordo com esse estudo, há viabilidade na aplicação do THAAS em campo livre, concluindo-se que podem ser adotados os mesmos valores normativos usados para o modo convencional de avaliação, ou seja, com fones (Feniman et al. 2012).

Lasee e Choi (2013) realizaram um trabalho com o objetivo de validar e fornecer confiabilidade ao "Auditory Vigilance Screening Measure" (AVSM), para ser utilizado como medida de atenção em crianças, e verificar se existia uma correlação significativa entre a pontuação de desatenção do AVSM e a classificação do professor escolar sobre a escala de Transtorno de Déficit de Atenção e Hiperatividade (TDAH). A casuística foi composta por 42 crianças entre cinco e nove anos. Os professores das crianças preencheram um questionário por aluno, que relatava detalhes sobre a atenção. O AVSM foi realizado em duas partes: A e $B$. Na parte $A$, uma palavra era dita a cada dois segundos e a criança deveria levantar sua mão sempre que ouvisse o número nove. A parte $B$ requeria que a criança levantasse sua mão sempre que a ordem numérica do três ao nove era apresentada. $O$ teste continha o total de 180 palavras. O resultado foi calculado da seguinte maneira: o número total de respostas corretas foi calculado pela soma de vezes que a criança levantou a 
mão na hora correta. Os erros de omissão foram obtidos pela soma do número de vezes que a criança deveria levantar a mão, mas não o fez. Os erros de comissão foram calculados pela soma do número de vezes que a criança levantou a mão em um momento em que a mão deveria ficar abaixada. Os autores relataram que os erros de omissão estavam associados com a desatenção e os erros de comissão estavam associados à impulsividade. Houve correlação significativa entre o AVSM e os relatos dos professores, sobre desatenção. Os autores relatam que embora o AVSM seja extremamente confiável, os resultados fornecem dados limitados como uma medida de diagnóstico de atenção, hiperatividade ou impulsividade.

Levav et al. (1998) realizaram uma pesquisa para verificar se existem semelhanças e diferenças em áreas específicas, na função neuropsicológica, entre pessoas com diferentes níveis de educação, diferentes faixas etárias e diferentes nacionalidades. A amostra foi composta de indivíduos de oito a 90 anos, dos Estados Unidos, Equador, Canadá, Irlanda e Israel. Psicólogos locais, psicólogos escolares e professores residentes no país participante administraram os testes, após terem recebido instruções padronizadas. As crianças realizaram uma bateria de testes para verificar a capacidade cognitiva: o "Continuous Performance Test", que tem o objetivo de verificar a vigilância e a atenção sustentada, utilizando tarefas visuais e auditivas do Teste de Desempenho Contínuo; o "Digital Symbol Substituition Test" (DSST), que tem como objetivo focalizar um alvo específico; o "teste de Stroop"; o "Digit Cancellation Test"; o "Standard and Distraction Forms"; o "Wisconsin Card Sorting Test" e o "Digit Span Test". Os adultos também realizaram os mesmos testes que as crianças, exceto o "Digital Symbol Substituition Test" (DSST), que foi substituído pelo "Wechsler Adult Intelligence Test" e "Trail Making Test" (TMT), adicionado somente aos testes para os adultos. Os resultados indicaram que as medidas de tempo de reação obtidas em testes de atenção sustentada são minimamente afetadas pelo país de origem e pelo nível de educação. Em contraste, os testes que avaliam a capacidade de focalizar atenção, resolver um problema, mudar estratégias e inibir uma resposta automática diferem significativamente por país e nível de educação. A maioria dessas diferenças tende a desaparecer na faixa etária dos 
54 anos. Os autores concluíram que os dados fornecem um suporte parcial para a hipótese de similaridades em algumas funções neuropsicológicas entre culturas.

\subsection{Cortisol}

O cortisol é um corticosteroide que é distribuído para todos os fluidos corporais, tais como, urina, suor, sangue ou saliva. Ele é produzido pelo córtex adrenal, que é parte da glândula adrenal, e geralmente referido como o "hormônio do estresse", uma vez que está envolvido na resposta ao estresse (Nieman et al. 2008, Patil et al. 2015). É controlado pelo eixo HipotálamoHipófise-Adrenal (HHA) (Jacobson 2005, Foley e Kirschbaum, 2010), um importante sistema neuroendócrino que auxilia o controle de cortisol adrenocortical. Em condições de equilíbrio, mantém o ritmo circadiano e é ativado em resposta ao estresse, deixando o organismo em sistema de alerta, preparando-o para enfrentar o fator estressor (Jacobson 2005, Aires 2008). Em seres humanos, a liberação do cortisol pelas glândulas suprarrenais ocorre no ponto final do eixo HHA (Jacobson 2005).

O eixo HHA é um grande sistema de resposta ao estresse fisiológico no corpo. Em resposta ao estímulo estressor interno ou externo, inicia-se a secreção da corticotrofina a partir do hipotálamo, o qual provoca a libertação do hormônio adrenocorticotrófico, pela hipófise. O hormônio adrenocorticotrófico, finalmente, provoca a secreção do cortisol, o glicocorticoide, a partir do córtex adrenal. $O$ cortisol entra no cérebro em quantidades significativas e provoca uma vasta gama de efeitos específicos de tecidos. Além de seu papel importante na regulação do estresse, o eixo HHA é vital para o funcionamento fisiológico normal (Chrousos 1998, Sapolsky et al. 2000, Belanoff et al. 2001, Despopoulos e Silbernagi 2003, Het et al. 2005, Tornhage e Alfven 2006).

Em condições basais, o cortisol mostra um ritmo circadiano, com menor secreção durante a primeira metade do sono noturno, com uma elevação durante a segunda metade do sono, e os níveis máximos são atingidos logo após o despertar. Durante o resto do dia, os níveis de cortisol decrescem continuamente, exceto nas ocorrências de estresse, que se 
sobrepõem sobre o ritmo circadiano (Van Cauter 1990, Despopoulos e Silbernagi, 2003, Aires 2008). Assim, no homem, as concentrações basais de cortisol são mais elevadas pela manhã (das 6 h00 às 9h00) com queda progressiva ao longo do dia e parte da madrugada (das $23 \mathrm{~h} 00$ às $3 \mathrm{~h} 00$ ). $\mathrm{O}$ ritmo circadiano do eixo hipotálamo-hipófise-adrenal é dependente do ciclo dianoite, do padrão de sono e vigília e do hábito alimentar, sendo alterado por ritmos de trabalho que trocam o dia pela noite e em viagens que modificam os fusos horários. A secreção dos glicocorticoides é regulada também, por fatores como estresse e citocinas inflamatórias, estresse físico, febre, cirurgia, queimadura, hipotensão arterial e hipoglicemia, que aumentam a secreção de cortisol (Aires 2008).

Qualquer tipo de estresse físico ou psicológico é capaz de gerar respostas hormonais do organismo, pela ativação do eixo hipotálamo-hipófiseadrenal (King e Hegadoren 2002, Kalman e Grahn 2004, Ali e Pruessner 2012, Maruyama et al. 2012). Estas respostas podem ser detectadas e mensuradas por meio da dosagem de cortisol circulante, que aumenta de 20 a 30 vezes após a exposição a um estímulo estressor, antes de diminuírem (King e Hegadoren 2002, Ali e Pruessner 2012, Maruyama et al. 2012). O cortisol aumenta a pressão arterial e o açúcar no sangue; também reduz a resposta imune (Nieman et al. 2008) e, em níveis maiores, reduz o desempenho da memória (Lima 2014). A mensuração do cortisol salivar pode fornecer informações importantes sobre o funcionamento do eixo HHA, sob condições normais e de estresse, assim como o envolvimento do cortisol nos mecanismos que determinam a atividade e a adaptação às mudanças ambientais (Jessop e Turner-Cobb 2008).

Pesquisas observacionais de estresse têm sido de difícil execução quando o público-alvo é infantil. Embora existam outras medidas fisiológicas, como frequência cardíaca, saturação de oxigênio, pressão arterial, glicose, catecolaminas e outros hormônios, exames para mensuração destas medidas podem ser altamente invasivos e não específicos para a resposta ao estresse. A coleta de saliva para análise do nível de cortisol permite uma medida precisa do cortisol que circula livre no sangue (Hiramatsu 1981, Umeda et al. 1981, Guechot et al. 1982, Riad-Fahmy et al. 1982, Woolston et al. 1983, Burke et al. 
1985, Vining e McGinley 1987, Laudat et al. 1988, Kirschbaum e Hellhammer 1989, Lo et al. 1992, Kirschbaum e Hellhammer 1994, Aardal e Holm 1995, Kiess et al. 1995, Shimada et al. 1995, Kirschbaum et al. 1996, Schmidt 1997, King et al. 2000, Kudielka et al. 2004, Morelius et al. 2004, Hanrahan et al. 2006, Lindauer et al. 2006, Silva et al. 2007, Hellhammer et al. 2009, McCarthy et al. 2009, Curcio et al. 2013, Kudielka et al. 2012, Patil et al. 2015, Nohara et al. 2016). É considerada uma técnica simples, pois necessita de pequena quantidade de saliva, entre 10 $\mathrm{\mu l}$ (Shimada et al. 1995, Morelius et al. 2004) e $25 \mu \mathrm{l}$ para realização da análise laboratorial (Castro e Moreira 2003, Kalman e Grahn 2004), não é invasiva e tem baixo custo; além disso, tem dupla vantagem em relação à amostra de sangue, por permitir a coleta sem o uso de agulha, o que poderia gerar um estresse adicional e interferir nos resultados (Hiramatsu 1981, Woolston et al. 1983, Burke et al. 1985, Vining e McGinley 1987, Kirschbaum e Hellhammer 1989, Lo et al. 1992, Kirschbaum e Hellhammer 1994, Aardal e Holm 1995, Kiess et al. 1995, Shimada et al. 1995, Santiago et al. 1996, Schmidt 1997, Martinelli et al. 1999, Raff 2000, Vedhara et al. 2000, Wust et al. $2000^{a}$, Tornhage 2002, Kalman e Grahn 2004, Morelius et al. 2004, Takai et al. 2004, Lindauer et al. 2006, Tornhage e Alfven 2006, Kiess e Pfaeffle 2007, Silva et al. 2007, Jessop e Turner-Cobb 2008, McCarthy et al. 2009, Marques et al. 2010, Golden et al. 2011, Kudielka et al. 2012, Gomes et al. 2015, Nederhof et al. 2015, Patil et al. 2015, Nohara et al. 2016), uma questão particularmente relevante nas pesquisas com crianças. Também, facilita a realização da coleta no domić́lio do participante, aspecto que pode aumentar as taxas de participação em estudos (Kahn et al. 1988, Lo et al. 1992, Antonini et al. 2000, Hanrahan et al. 2006, Jessop e Turner-Cobb 2008, Patil et al. 2015).

Os níveis de cortisol salivar influenciam fortemente a função cerebral, afetando a conectividade emocional, visual e cognitiva de maneiras opostas às que deveriam responder (Henckens et al. 2012). Existem alguns artigos que estudam a relação dos efeitos do estresse e os altos níveis de cortisol, relatando sempre efeitos negativos nos quesitos estudados, tais como: humor, atenção e irritação (Kirschbaum et al. 1996, van Honk et al. 1998, Vedhara et al. 2000, Ellenbogen et al. 2002, Kalman e Grahn 2004, Lindauer et 
al. 2006, Roelofs et al. 2007, Jessop e Turner-Coob 2008, Patil et al. 2015). Ellenbogen et al. (2002) referiram que o estresse negativo atrapalha a informação verbal e que a falta de atenção está associada ao alto nível de cortisol.

Embora a análise de cortisol salivar mensure precisamente a ansiedade (Umeda et al. 1981, Kirschbaum e Hellhammer 1989, Kirschbaum e Hellhammer 1994, Aardal e Holm 1995, Kiess et al. 1995, Shimada et al. 1995, Schmidt 1997, King et al. 2000, Kudielka et al. 2004, Hanrahan et al. 2006, Hellhammer et al. 2009, McCarthy et al. 2009, Patil et al. 2015, Nohara et al. 2016), uma série de fatores que podem interferir nos níveis de cortisol precisa ser controlada pela equipe de pesquisa, antes de utiliza-lo em pacientes pediátricos (Hanrahan et al., 2006). Alguns desses fatores são:

- Padronização do horário para a coleta das amostras: idealmente, as amostras devem ser coletadas em um momento semelhante, para todos os sujeitos (Hanrahan et al. 2006, Kiess e Pfaeffle 2007). Nos seres humanos, a secreção de cortisol pelas glândulas suprarrenais segue um ciclo, com um aumento acentuado do cortisol após acordar. Este aumento é um fenômeno chamado de "resposta de despertar do cortisol", que parece ser uma característica distinta do eixo hipotálamo-hipófise-adrenal (Wust et al. $2000^{\mathrm{b}}$, Fries et al. 2009). A quantidade de cortisol presente na saliva sofre variações durante o dia. Nas duas ou três primeiras horas após o despertar há um pico hormonal (Nieman et al. 2008). Portanto, para reduzir o impacto da variação diurna dos níveis de cortisol, é indicado que as pesquisas com coleta de saliva sejam realizadas na parte da tarde, entre 12 e 18 horas, quando os níveis de cortisol estão relativamente estáveis (McCarthy et al. 2009, Henckens et al. 2012).

- Controle de determinados alimentos, bebidas e medicamentos: para maior precisão dos resultados e um bom controle da variação do cortisol, restrições dietéticas também são indicadas, como evitar a ingestão de produtos à base de cafeína, pois certos alimentos ou bebidas lácteas, principalmente aqueles 
que contêm cafeína, podem alterar os níveis de cortisol e/ou o pH salivar (Aardal e Holm 1995, Vedhara et al. 2000, Hanrahan et al. 2006, Kiess e Pfaeffle 2007, McCarthy et al. 2009). O tempo de abstenção de alimentos e bebidas descrito nas pesquisas, entretanto, não é o mesmo. Alguns autores relatam a necessidade de jejum de 15 a 30 minutos anteriores à coleta de saliva (Hanrahan et al. 2006), enquanto outros indicam uma hora (Aardal e Holm 1995, Vedhara et al. 2000, Ellenbogen et al. 2002) ou até duas horas (Kalman e Grahn 2004). Caso alguma criança tenha comido 30 minutos antes da coleta, pode ser solicitado a ela que enxague a boca e espere de três a cinco minutos, tempo suficiente para reestabelecer o pH salivar (Hanrahan et al. 2006). Crianças que ingeriram esteroides orais nos 30 dias anteriores devem ser excluídas da amostra. No entanto, as crianças que utilizaram esteroides tópicos e/ou inalados podem participar da pesquisa, pois a absorção sistêmica é limitada e não interfere nos níveis de cortisol (Hanrahan et al. 2006).

- Estabelecimento de procedimentos e protocolos: as amostras devem ser coletadas de forma padronizada e transportadas em recipiente próprio, logo que possível, para o laboratório de análise. $O$ descongelamento e recongelamento devem ser evitados, pois podem resultar em níveis significantemente mais baixos de cortisol (Aardal e Holm 1995).

- Separação de amostras: Quando a variável é o sexo, alguns autores afirmam que a pesquisa se torna mais confiável quando as amostras entre meninos e meninas são separadas (Hanrahan et al. 2006); outros afirmam que não há esta necessidade (McCarthy et al. 2009) ou desenvolveram pesquisas em um só grupo (Groschl et al. 2003). Jessop e Turner-Coob (2008) consideraram que, quando o assunto é a variação do cortisol, esta pode ser uma variável dependente que ainda não foi investigada de forma sistemática. 
- Uso de métodos e materiais de coleta confiáveis: os materiais e técnicas utilizados para a coleta das amostras podem influenciar a precisão do resultado. Os corticosteroides, tais como o cortisol, têm afinidade com plástico e podem ligar-se às paredes de tubos de coleta. O uso de um dispositivo específico para coleta das amostras é altamente recomendado.

- Uso de ensaios altamente específicos: os kits de análise das amostras devem ser específicos e adequados para cortisol salivar. Valores de referência para esses ensaios específicos precisam ser disponibilizados por cada um dos laboratórios (Kiess e Pfaeffle 2007).

É importante que os métodos de análise sejam usados separadamente a cada pesquisa, uma vez que a sensibilidade dos ensaios difere consideravelmente (Kiess e Pfaeffle 2007). Embora alguns artigos estabeleçam valores de referência, estes divergem consideravelmente. Por exemplo, as concentrações matinais de cortisol na saliva relatadas por Silva et al. (2007) para crianças de três meses a 45 dias, correspondem, em média, a $557,86 \mathrm{nmol} / \mathrm{L}$ e variam entre 76,88 e 1.620,08 nmol/l, enquanto Kiess et al. (1995) apresentam valores que variam de $4,3 \mathrm{nmol} / \mathrm{L}$ a $81,3 \mathrm{nmol} / \mathrm{L}$ para a mesma faixa etária; Rosmalen et al. (2005) relatam valores que variam de 1,90nmol/L a 16,02 para crianças de 10 a 12 anos e Tornhage e Alfven (2006) apresentam níveis matinais de $8,8 \mathrm{nmol} / \mathrm{L}$ em crianças de seis a 15 anos.

Schmidt (1997) relatou que, embora os valores basais não estejam bem estabelecidos, isso não impede o uso de cortisol salivar em pesquisa com crianças, pois o próprio indivíduo atua como controle em situações experimentais, podendo ser ele mesmo o melhor valor de referência.

Kirschbaum et al. (1996) realizaram um estudo com adultos, para investigar se há associação entre os níveis de cortisol e a memória. A amostra foi composta de cinco mulheres e oito homens. Todos eles tiveram que se abster de exercício físico, estresse psicológico, grandes refeições, bebidas com baixo $\mathrm{pH}$ e tabagismo, por pelo menos uma hora antes do experimento. Os sujeitos foram expostos ao "Trier Social Estresse Test" (TSST), que consiste 
em pedir para que cada participante discursasse em público por cinco minutos e depois realizasse uma tarefa aritmética mentalmente, por mais cinco minutos. Dez minutos após a cessação do estresse, os sujeitos receberam uma lista com 24 nomes, com a instrução para decorá-los durante os próximos cinco minutos. Depois de uma tarefa de distração, que durou cinco minutos, foi solicitado que os participantes recordassem e anotassem todas as palavras que começassem com a sílaba "MO", sem limite de tempo. A lista foi composta por 10 palavras que começavam com essas sílabas. Amostras de saliva foram coletadas, utilizando o tubo Salivette $\AA$, cinco minutos antes e 10 minutos após o TSST. A análise da saliva mostrou o aumento nos níveis de cortisol salivar em resposta ao TSST. Os níveis de cortisol aumentaram significativamente de 8,46 $\mathrm{nmol} / \mathrm{L}$ para 17,65 nmol /L. Nove dos 13 pacientes apresentaram uma elevação de mais de 2,5 $\mathrm{nmol} / \mathrm{L}$ após o TSST, isto é, uma resposta de cortisol clara ao estressor psicossocial. Os níveis de cortisol em homens foram mais pronunciados do que nas mulheres. Embora as mulheres tendessem a lembrar de mais palavras do que os homens, essa diferença não foi estatisticamente significativa. Os resultados indicaram uma relação negativa significativa entre os níveis de cortisol induzida pelo estresse e o desempenho na tarefa de memória, ou seja, indivíduos com alta resposta de cortisol ao estressor mostraram menor desempenho da memória.

Ellenbogen et al. (2002) realizaram um estudo para examinar o humor, a atividade adrenocortical e o nível de atenção, após submissão dos participantes a seguidos estímulos estressantes. A casuística compôs-se de 135 pessoas, entre 18 e 36 anos de idade, que foram divididos em três grupos: os que receberam estímulos de estresse negativo, os que receberam estímulos de estresse positivo e participantes em condições neutras. Os grupos de estresse positivo e negativo estavam em competição, por meio de um programa de computador, com recompensa monetária para o participante que vencesse. A resposta emocional foi medida durante o teste Perfil de Humor. A coleta de saliva foi feita com uma tira de papel absorvente, inserida na região sublingual até que o papel estivesse saturado de saliva. As coletas foram realizadas em quatro tempos diferentes: com o participante relaxado, submetido à tarefa causadora de estresse, submetido à tarefa de atenção e 
durante a fase de recuperação. As amostras foram congeladas antes das análises dos níveis de cortisol, que foram mensurados mediante radioimunoensaio, utilizando-se um kit comercial específico. O estudo pôde verificar que participantes em condições de estresse negativo foram mais rápidos em realizar o teste e que escores elevados de depressão estavam associados a níveis baixos de cortisol durante a fase inicial e níveis mais elevados durante a fase de recuperação.

Lipp (2003) definiu o estresse como uma relação particular entre a pessoa e o ambiente, quando este é avaliado pelo indivíduo como uma ameaça que excede seus recursos pessoais. $O$ autor também relacionou o estresse com processos psicológicos, justificando que é a percepção cognitiva que o indivíduo possui diante da situação vivenciada que interfere na avaliação psicológica, podendo envolver situações de perigos, desafios, ameaças e, assim, obter ou não a capacidade de manejar esta situação.

Eventos que seriam descritos por muitos como banais ou insignificantes, também podem ser geradores de estresse, segundo Novais e Frota (2003), dependendo muito de características próprias de personalidade, de experiências anteriores (principalmente na síndrome de estresse-póstraumático), do grau de maturidade do indivíduo e das próprias influências ambientais do momento. Os autores pontuam que a idade é também um aspecto altamente importante, pois para cada faixa etária os fatores estressantes têm representatividade diferente.

A afirmação de que o estresse tem profunda influência sobre os recursos de atenção do cérebro e pode induzir a um estado de hipervigilância, otimizando a detecção de possíveis "ameaças" foi feita por Henckens et al., (2012). Os autores relataram que os corticosteroides têm se mostrado profundamente influentes, de maneira tempo-dependente e verificaram, por meio de imagens de ressonância magnética, como esses efeitos tempodependentes, no mecanismo neural, influenciam a atenção seletiva e a inibição da distração emocional. Participaram da pesquisa 65 homens, que foram divididos em três grupos: um grupo recebeu duas capsulas de placebo; o segundo grupo, 270 minutos antes da realização do teste, recebeu uma cápsula de placebo, 60 minutos antes de realizar as tarefas exigidas na 
pesquisa, recebeu $10 \mathrm{mg}$ de hidrocortisona; o terceiro grupo recebeu $10 \mathrm{mg}$ de hidrocortisona, 270 minutos antes de realizar as tarefas, seguido de cápsula de placebo, faltando 60 minutos. As tarefas consistiam em identificar cores e palavras o mais rápido possível. Imagens da ressonância magnética foram gravadas, enquanto os participantes realizavam o teste de distração emocional, o que permitiu examinar tanto a atenção sustentada, quanto a atenção seletiva. Os resultados obtidos com o grupo de administração rápida de cortisol (60 min) permitiram concluir que o efeito rápido dos corticosteroides pode contribuir para um estado de hipervigilância. Entretanto, os resultados obtidos com a administração lenta de cortisol indicaram uma redução na ativação visual do cérebro, relacionada ao processamento da atenção sustentada. De maneira geral, a pesquisa mostrou que os corticosteroides influenciam na função cerebral de maneira tempo-dependente, afetando a conectividade emocional, visual e cognitiva.

Situações estressantes causam uma grande variedade de respostas adaptativas no cérebro, bem como em outros sistemas do corpo humano. Em um estudo realizado com 33 estudantes da Universidade de Nova Southeastern, pesquisadores investigaram os efeitos relacionados ao tempo pós-exposição a uma situação de estresse aguda sobre a atenção sustentada e o processamento da emoção. Os autores encontraram um decréscimo do nível de atenção pós-exposição à situação que desencadeou o estresse agudo nos participantes e isso foi observado principalmente no grupo experimental, quando o cortisol se encontrava em níveis mais elevados em relação ao observado no grupo controle (Cosenza e Guerra 2011).

Após realizar algumas pesquisas nas quais afirmaram que 0 estresse psicológico pode alterar o processo cognitivo, Qi et al. (2016) relataram que havia algumas limitações nessas pesquisas anteriores, especialmente em relação aos métodos utilizados com os grupos controle e de teste, o que poderia ter influenciado na performance dos participantes. Então, realizaram um estudo para investigar o estresse subjetivo, o cortisol salivar e os efeitos do estresse psicológico sem a presença de vieses. Quinze voluntários participaram da pesquisa. O teste consistia em, mentalmente, efetuar a multiplicação de dois números decimais. $O$ grupo foi submetido a 
duas condições experimentais: em uma delas os cálculos deveriam ser feitos com limite de tempo estabelecido para a sua realização (condição de estresse) e, na outra, não havia limite de tempo para fazê-lo. Coletas de saliva foram realizadas durante todo o experimento. Os resultados mostram valores maiores de estresse, ansiedade e efeitos negativos durante a fase em que os indivíduos foram submetidos à condição de estresse do que na fase controle. O nível de cortisol na saliva também aumentou depois da condição de estresse, mas teve uma grande diminuição depois, na condição de controle. Os autores concluíram que a pressão de tempo proporcionou um nível de estresse psicológico que aumentou os níveis de cortisol salivar e causou efeitos negativos na execução do teste.

O Transtorno de Estresse Pós-Traumático (TEPT) é um transtorno de ansiedade resultante da exposição a um evento traumático. Este transtorno foi estudado por Lindauer et al. (2006) em policiais e suas características clínicas principais são: lembranças do trauma, evasão de estímulos associados com o acontecimento e sintomas persistentes de excitação aumentada. Os autores relataram que o TEPT tem sido associado a deficiências de cortisol, problemas relacionados à memória e ao volume do hipocampo. Assim, realizaram um estudo para examinar os níveis de cortisol salivar de policiais (com e sem TEPT), bem como avaliar o funcionamento neuropsicológico e correlacionar o tamanho dos hipocampos com níveis de cortisol, aprendizagem, memória e desempenho de atenção, em indivíduos com TEPT. Vinte e quatro policiais participaram do estudo: 12 com TEPT e 12 que passaram por experiência traumática, mas nunca tiveram TEPT. Os kits para coleta de saliva (Salivette ${ }^{\circledR}$ ) foram distribuídos aos participantes, que foram orientados oralmente como deveriam proceder. As amostras foram obtidas em três momentos: pela manhã, às $16 \mathrm{~h} 00$ e antes de dormir. Após a coleta, as amostras foram congeladas a $-20^{\circ} \mathrm{C}$ e a mensuração do cortisol foi realizada por quimiluminescência. Para avaliar funções de aprendizagem, memória a curto e longo prazo e a vulnerabilidade em efeitos de interferência, os autores utilizaram o California Verbal Learning Test. O volume do hipocampo foi mensurado por meio de imagens de ressonância magnética. Os indivíduos com TEPT apresentaram menores volumes nos hipocampos esquerdo e direito. Na 
análise do cortisol salivar, o grupo com TEPT apresentou valores mais elevados na amostra realizada pela manhã. Correlações negativas foram encontradas entre o grupo com TEPT e o teste de memória. Uma correlação positiva foi encontrada entre o nível de cortisol salivar, na amostra da manhã e o volume do hipocampo direito. O grupo sem TEPT não apresentou correlação com perda de memória, tamanho do hipocampo diminuído e alto nível de cortisol. Os autores concluíram que hipocampos menores, níveis mais altos de cortisol e perda de memória, estão associados ao TEPT e que problemas de memória não parecem ser uma consequência direta do tamanho do hipocampo.

Um estudo realizado por Vedhara et al. (2000) examinou se as mudanças nos níveis de corticosteroides durante um estresse natural ou agudo poderia alterar a função cognitiva. Sessenta estudantes participaram do estudo e, em sua primeira fase, fizeram um relato a respeito do nível de estresse experimentado durante o período sem provas e durante o período de provas. Para determinar os níveis de cortisol, os participantes coletaram cinco amostras de saliva por dois dias consecutivos, durante ambos os períodos, sem e com provas, utilizando o dispositivo Salivette ${ }^{\circledR}$. Os níveis de cortisol foram determinados pelo uso do Kit de Cortisol Elisa. Para avaliação da função cognitiva, os participantes fizeram um teste de memória de curto prazo, no qual 20 palavras thes eram apresentadas e depois tinham que relatar o maior número de palavras que conseguissem. Os testes restantes de memória e atenção foram retirados do Teste de Atenção Diária, avaliando a memória verbal auditiva, atenção seletiva e atenção dividida. Os resultados dos níveis de cortisol foram significantemente maiores durante o período de provas. As cinco amostras de saliva possibilitaram verificar se havia diferença entre os sujeitos, de três formas distintas: em relação à presença de provas ou não; entre os dois dias coletados; e, nos momentos (horas) em que foram coletadas. Os resultados revelaram que o nível de cortisol diferiu entre o período com e sem provas e também ao longo do dia. No entanto, não houve interações significativas entre um dia e o outro. Embora não houvesse provas do declínio esperado dos níveis de cortisol, estes foram significantemente mais elevados no período sem provas em comparação com o período de provas. Os 
resultados revelaram que os participantes tiveram melhor desempenho no teste de memória de curto prazo durante o período de provas. Já nos testes de atenção seletiva e dividida, os participantes tiveram melhores atuações durante o período sem provas. O teste de memória auditiva verbal não diferiu significantemente entre os grupos.

Verdejo-Garcia et al. (2015) realizaram um estudo para verificar se adolescentes com excesso de peso são mais sensíveis ao estresse social e, portanto, mais sensíveis aos efeitos nocivos do estresse na cognição. A amostra foi composta de 84 adolescentes, com idades entre 12 a 18 anos. Os participantes foram separados em dois grupos, com base na porcentagem de massa corporal: peso normal e excesso de peso. Ambos os grupos foram expostos ao estresse social, induzido pelo Trier Social: os participantes tiveram que fazer um discurso sobre suas qualidades e defeitos na frente de um público virtual. Foram realizados testes para tomada de decisões e de atenção e colhidas amostras de saliva antes e depois do discurso. Os resultados mostraram que os adolescentes com excesso de peso apresentavam maiores níveis de cortisol e pior desempenho da atenção após o estressor social, em comparação com o grupo de peso normal. O desempenho no teste de tomada de decisão diminuiu após o estressor social, em ambos os grupos. Os autores concluíram que os que estão com sobrepeso ou obesos têm maior sensibilidade ao estresse social, o que afeta negativamente as habilidades de atenção.

Em seu estudo, Nohara et al (2016) coletaram amostras de saliva de ratos para mensurar a quantidade de cortisol presente, após terem sido submetidos a estresse. A amostra foi dividida em dois grupos: um grupo recebeu contenção física em um cilindro transparente de acrílico e o outro seguiu sem contenção. Os ratos foram tratados com uma injeção intraperitoneal de 2,0 mg/kg de cortisol, seguida de uma injeção de anestésico, aplicada 10 minutos após a injeção de cortisol. A coleta de saliva foi feita durante 40 minutos, com um cotonete. Após a coleta de saliva, os ratos foram decapitados e o sangue do tronco foi recolhido em tubos de amostra. Os resultados demonstram que o cortisol exógeno foi detectado na saliva e no plasma, ou seja, os níveis de cortisol na saliva refletem os seus níveis no 
plasma. A imobilização aumentou significativamente os níveis de cortisol no plasma e saliva. Os autores concluíram que cortisol salivar é útil como biomarcador biológico.

Gassling et al. (2012) referiram que as fissuras labiopalatinas tornam necessário um tratamento de muitos anos, desde o nascimento até a idade adulta, e isso provoca uma variedade de fatores estressantes que podem causar um impacto de longa duração sobre os indivíduos afetados, no decorrer de suas vidas. Os autores realizaram um estudo com o objetivo de avaliar diferentes aspectos do estresse psicossocial em indivíduos adultos com fissura labiopalatina. A amostra foi dividida entre dois grupos: o grupo experimental, composto de 30 pacientes entre 18 e 49 anos, com fissura transforame unilateral, e o grupo controle, com 30 pacientes sem fissura labiopalatina, com idades entre 18 e 51 anos. Os indivíduos foram expostos ao Trier Social Stress Test (TSST), que consiste em discursar em público e, em seguida, realizar cálculos matemáticos de nível difícil. Com 0 auxílio do Salivette ${ }^{\circledR}$, foram coletadas amostras de saliva, para posterior determinação dos níveis de cortisol em diferentes momentos: 45 minutos e dois minutos antes do TSST, e um, 10, 20, 30, 45 e 60 minutos após o TSST. As amostras foram armazenadas a $-20^{\circ} \mathrm{C}$ até a análise. Após a última coleta de saliva, os participantes preencheram um questionário de 19 itens, que mensurava a capacidade de enfrentamento do estresse. Após a realização do TSST, houve um aumento semelhante nas concentrações de cortisol em ambos os grupos. Posteriormente, o declínio nas concentrações de cortisol foi significativamente mais rápido no grupo experimental. Em particular, diferenças significativas foram encontradas nos níveis de cortisol entre os grupos de 45 e 60 minutos. A avaliação do questionário de enfretamento de estresse mostrou diferenças significativas entre os grupos, evidenciando que o grupo com fissura labiopalatina apresentou um maior potencial de enfrentamento a eventos intensamente estressantes, em relação ao grupo controle.

Gomes et al. (2016) realizaram um trabalho com 39 crianças de dois a cinco anos, encaminhadas para tratamento odontológico sob sedação, devido a um comportamento negativo em consultas anteriores. Os autores levantaram a hipótese de que a profilaxia dentária profissional gera estresse nas crianças, 
alterando os níveis de cortisol. Um odontopediatra realizou um exame odontológico, seguido de profilaxia com pedra-pomes e taça de borracha na baixa rotação. Nenhuma das crianças foi sedada durante a profilaxia ou exame dentário. Um observador registrou a condição bucal de cada criança, utilizando o índice CPO-D, da Organização Mundial de Saúde, que classifica os dentes entre: cariados, perdidos ou restaurados. As crianças que não colaboraram foram estabilizadas pelo pai ou mãe, presente durante todo o procedimento. Três amostras de saliva, utilizando o dispositivo Salivette® (Sarstedt Inc., Nümbrecht, Alemanha) foram coletadas para a pesquisa: na recepção do consultório odontológico, logo quando a criança chegou; 25 minutos após a profilaxia; e, em um dia anterior ao dia da consulta, logo após a criança acordar. No final do procedimento o odontopediatra avaliou o comportamento clínico das crianças, de acordo com a versão brasileira da Escala Venham Behaviour Rating, que é classificada da seguinte forma: 0- cooperação total; 1protesto moderado; 2- protesto intenso; 3- protesto mais intenso; 4- protesto generalizado. As amostras foram congeladas a $-80^{\circ} \mathrm{C}$ até 0 momento da análise. Das 39 crianças avaliadas, 36 apresentavam cáries dentárias que necessitavam de restauração, pulpectomia ou extração. Sessenta e seis por cento $(66,6 \%)$ das crianças apresentaram algum comportamento de protesto (1, 2, 3 ou 4) durante o exame dental. A comparação dos níveis de cortisol salivar das crianças mostrou que, no dia anterior, ao acordar e no momento da profilaxia dentária, os níveis de cortisol foram significantemente maiores do que no momento da chegada ao consultório odontológico. Os níveis de cortisol salivar foram maiores na amostra após o término da profilaxia do que a amostra realizada na recepção no consultório. A profilaxia dental profissional foi relacionada ao estresse em crianças com histórico de problemas de controle de comportamento durante procedimentos odontológicos. Além disso, os níveis de cortisol salivar durante profilaxia dentária profissional aumentaram em crianças que tinham atividade de cárie dental com exposição da polpa; crianças que não completaram com sucesso um tratamento dentário anterior; pela dificuldade de controle do comportamento; crianças com relato de dor de dente; crianças que apresentaram comportamento de protesto e/ou crianças que precisaram ser estabilizadas pelos pais durante um exame clínico odontológico. 
Kudielka e Kirschbaum (2003) realizaram um trabalho comparando sujeitos que acordaram entre 4h55min e 12h03min e verificaram que a hora de acordar influenciou fortemente os níveis de cortisol. Em outra pesquisa, realizada com enfermeiras que trabalham em turnos da manhã e que acordam muito cedo (entre 4 h00 e 5h30min), foi possível observar que elas tiveram um tempo mais prolongado para baixar os níveis de cortisol do que aquelas do turno do dia tardio (entre $6 \mathrm{~h} 00$ e 9h00) ou o turno da noite (entre as $11 \mathrm{~h} 00 \mathrm{e}$ 14h00). Os autores concluíram que acordar mais cedo aumenta os níveis de cortisol. Scheer e Buijs (1999) e Thorn et al. (2004) realizaram pesquisas semelhantes e encontraram níveis maiores de cortisol nos sujeitos que acordaram com luz do que aqueles que acordaram na escuridão. No entanto, não há relatos de diferença nos níveis de cortisol em sujeitos que acordam com despertador ou espontaneamente (Wust et al., 2000 ${ }^{\text {b }}$.

Thorn et al. (2004) encontraram maiores níveis de cortisol ao acordar, em dia de trabalho do que em um dia de final de semana ou de folga. Para Schlotz et al. (2004), em estudo semelhante, essa diferença está associada à preocupação e à sobrecarga de trabalho. Independentemente do sexo, horário de despertar, tempo de duração do sono, os participantes que relataram níveis mais elevados de trabalho mostraram níveis médios mais elevados de cortisol após o despertar durante a semana do que em dias de fim de semana. Também foram encontrados altos níveis de cortisol em sujeitos com estresse crônico ou agudo (Wust et al. 2000ª Rohleder et al. 2007).

\subsubsection{Cortisol em crianças}

Em pediatria, o medo e a ansiedade são considerados grandes obstáculos na interpretação dos exames laboratoriais do eixo hipotálamohipófise-adrenal (HHA) devido aos procedimentos de coleta invasivos (como a punção venosa) e pelo contato com pessoas estranhas (médicos e grupo de enfermagem), o que favorece o estresse, alterando os resultados de dosagem de cortisol (Castro e Moreira 2003).

O sangue e a urina são os meios mais utilizados para dosar 0 
cortisol basal, mas são recursos que apresentam aspectos negativos, por necessitarem de punção venosa e pela dificuldade de coleta de urina sem perdas, durante 24 horas, especialmente nos lactentes e nas meninas (Castro et al. 1999)

Morelius et al. (2004) realizaram uma pesquisa com o objetivo de verificar a eficiência do método de radioimunoensaio para análise na detecção de baixos níveis de cortisol na saliva, em recém-nascidos internados na UTI neonatal, que recebiam glicose oral. De acordo com Skogsdahl et al. (1996) e Gradin et al. (2002), a administração de glicose por via oral antes de um procedimento doloroso, como uma punção venosa, por exemplo, minimiza o estresse do procedimento, uma vez que a solução de glicose possui um efeito analgésico antes mesmo de chegar ao estômago e que seus efeitos são provavelmente mediados por mecanismos neuro-humorais que envolvem os opioides endógenos. As autoras coletaram saliva dos recém-nascidos por meio de dois cotonetes, unidos por um fio de sutura e um pedaço de fita adesiva cirúrgica, que foi posicionado na boca do bebê por dois minutos. Após a coleta, os cotonetes foram colocados dentro de um tubo de plástico e centrifugados. $A$ saliva foi congelada e armazenada a $-70^{\circ} \mathrm{C}$ até a análise. A pesquisa mostrou que foi possível realizar o teste de radioimunoensaio com apenas 10 microlitros de saliva, $(\mu \mathrm{l})$ em 113 recém-nascidos, e que a glicose utilizada para o alívio da dor não interferiu no método de análise do cortisol. Os autores concluíram que é possível recolher quantidade suficiente de saliva para análise mesmo com concentrações muito baixas de cortisol em recém-nascidos. Também é possível oferecer glicose por via oral ao bebê, antes de um procedimento doloroso, e ainda mensurar o cortisol salivar de forma confiável.

Um estudo com crianças de quatro a 10 anos foi realizado por McCarthy et al. (2009), comparando os níveis de cortisol obtidos durante um dia rotineiro e em outro dia, no qual as crianças passariam por procedimento endovenoso em uma clínica médica. Para a mensuração do cortisol, foram realizadas algumas coletas de saliva. A análise do cortisol salivar foi utilizada para o estudo da resposta fisiológica das crianças a estímulos estressantes e dolorosos. A amostra foi composta de 384 crianças. Para a coleta de saliva foi oferecida uma goma de mascar sem açúcar como estimulante salivar. A goma 
era descartada entre três e cinco minutos e, em seguida, as crianças cuspiam ou deixavam a saliva escorrer pelo tubo de coleta. Quatro amostras de saliva foram realizadas: no momento em que a criança chegou à clínica para realização do procedimento endovenoso, para avaliar o nível de estresse da criança antes do procedimento; 20 minutos após o cateter endovenoso ser inserido, representando a resposta ao estresse durante o procedimento. As outras duas amostras foram coletadas em casa, pelos pais, pelo menos 24 horas antes do procedimento na clínica médica, em um dia comum, quando a criança não iria ter nenhuma experiência de estresse. Os pais foram instruídos a obter as amostras nos mesmo horários em que iriam ser realizadas no dia seguinte, na clínica. Os participantes do estudo foram instruídos para não comer ou beber 30 minutos antes da coleta, para controle de possíveis alterações no cortisol salivar relacionado com alimentos e bebidas. Se por acaso alguma criança tivesse ingerido qualquer tipo de comida ou bebida menos de 30 minutos antes da coleta, ela era instruída a enxaguar a boca e a esperar por três a cinco minutos. As amostras foram congeladas a $-20^{\circ} \mathrm{C}$ até a realização da análise laboratorial. As amostras realizadas em casa determinaram os valores normativos de cortisol salivar das crianças. Comparando-se os níveis de cortisol das amostras realizadas na clínica, observou-se um aumento no cortisol, da primeira amostra para a segunda. Os níveis de cortisol observados nas amostras realizadas na clínica médica foram maiores do que os das amostras realizadas em casa. Os autores concluíram que o cortisol salivar é uma medida biológica precisa de estresse da criança e que o estudo poderá contribuir para o conhecimento das respostas individuais das crianças e consequente utilização de intervenções eficazes, capazes de minimizar o sofrimento da criança durante os procedimentos médicos.

Curcio et al. (2013) realizaram um estudo para determinar os níveis de cortisol em 19 crianças entre sete e dez anos, que seriam atendidas na clínica da disciplina de Odontopediatria da Faculdade de Odontologia, da Universidade Federal de Juiz de Fora (UFJF). As amostras foram coletadas dentro da clínica odontológica, com ajuda do kit Salivette $\AA$, na primeira consulta da criança, antes e imediatamente depois de uma consulta em que se realizou um exame clínico, diagnóstico e plano de tratamento. Após a 
realização da consulta, em 14 crianças da amostra, o nível de cortisol salivar foi menor do que antes dela, com diferença estatisticamente significativa. Os autores concluíram que a espera de uma consulta odontológica mostrou ser um fator estressor entre crianças. Destacaram ainda, que o conhecimento dos eventos biológicos relacionados à ansiedade ao tratamento odontológico tem implicações clínicas, ou seja, revela que a criança precisa que um tempo maior seja dispendido para a sua adaptação ao tratamento, o que poderá contribuir para sua maior aceitação ainda na infância.

De acordo com Patil et al. (2015), existe uma correlação entre o cortisol salivar e estresse, em procedimentos odontológicos. Este grupo de pesquisadores realizou um estudo com os objetivos de: avaliar as mudanças nos níveis de cortisol salivar em diferentes procedimentos odontológicos em crianças, verificar se o tipo de relação existente entre o estresse e o cortisol salivar e identificar qual procedimento odontológico era mais estressante. Os autores relataram que medo e dor eram os fatores que produziam estresse e que havia evidências de que o medo de dentista adquirido na infância poderia persistir e influenciar o comportamento de um adulto diante de um tratamento odontológico considerado estressante e produtor de ansiedade. Foram selecionadas 20 crianças entre quatro e oito anos, que precisavam da realização de ao menos uma restauração e uma extração. Em todos os pacientes foram realizados três procedimentos, em três dias diferentes: exame físico (intra e extraoral), restauração e extração. As amostras de saliva foram coletadas 10 minutos antes de cada procedimento, durante o procedimento e 30 minutos depois, em três dias diferentes. No primeiro dia, quando foi realizado somente o exame físico, não houve diferença significativa entre os níveis de cortisol na saliva, nas três amostras do dia (antes, durante e depois do exame). Contudo, na segunda visita ao dentista, quando foi realizada uma restauração, houve uma diferença significativa dos níveis de cortisol salivar: foram encontrados valores elevados de cortisol salivar na preparação da cavidade. No terceiro dia, houve um aumento dos níveis de cortisol após a realização da extração. Os autores concluíram que existe uma correlação entre o cortisol salivar e o estresse em procedimentos odontológicos, e que o procedimento restaurador é mais estressante em crianças; por isso, métodos 
alternativos devem ser usados em crianças ansiosas.

Gomes et al. (2015) realizaram um estudo para avaliar os níveis de cortisol salivar em 18 crianças de dois a cinco anos de idade, sedadas com Midazolam por via oral durante a anestesia local, para tratamento restaurador. Também, avaliaram a relação entre o cortisol salivar e o comportamento da criança mensurado por uma escala de observação. Os autores relataram que um dos problemas mais difíceis durante o tratamento odontológico, em crianças nessa faixa etária, é o controle do comportamento. Observaram que a anestesia local é a causa mais comum de ansiedade e estresse, além de fatores como a baixa idade, experiências anteriores negativas e dor de dente, aspectos que contribuem para o comportamento negativo durante 0 atendimento odontológico. A hipótese deste trabalho era que o Midazolam iria reduzir o estresse e melhorar o comportamento durante 0 tratamento odontológico. As crianças que participaram na pesquisa necessitavam de pelo menos dois procedimentos restauradores e haviam apresentado comportamento negativo durante as consultas odontológicas. A amostra foi dividida em dois grupos, aos quais foram administrados xarope de Midazolam (Dormire® $2 \mathrm{mg} / \mathrm{mL}$, Cristália, Brasil) e placebo por via oral, respectivamente. Após a administração, a criança foi monitorizada durante 15 minutos e, em seguida, levada para a cadeira odontológica, para o início do procedimento odontológico. As amostras de saliva foram coletadas em tubos Salivette®, em quatro momentos diferentes: no dia anterior à consulta, em casa, pelos pais, logo quando a criança acordou; no momento da chegada à clínica odontológica, no dia do procedimento; 25 minutos após a anestesia local e 25 minutos após o procedimento. A amostra realizada após a anestesia apresentou níveis de cortisol mais baixos no grupo que recebeu Midazolam do que o grupo placebo, mas não houve diferença estatisticamente significativa nos níveis de cortisol entre os grupos nos outros tempos de coleta de saliva. $O$ comportamento observado, de acordo com a escala observacional OSUBRS, variou muito com a predominância da pontuação "4" (lutando) durante anestesia local em ambos os grupos. O grupo placebo teve uma maior percentagem de pontuação 3 (movimento sem chorar) durante a anestesia. Após o tratamento, o comportamento das crianças dos dois grupos foi 
semelhante. Não houve correlação estatisticamente significativa entre os níveis de cortisol salivar e o comportamento das crianças em qualquer momento da amostra para qualquer um dos grupos. Os autores concluíram que o Midazolam oral pode ajudar a reduzir os níveis de cortisol salivar em crianças durante o tratamento odontológico e, especialmente, durante a anestesia local, mas sua eficácia clínica, em relação ao comportamento, neste grupo etário é questionável.

Saliba et al. (2016) realizaram um estudo com crianças de seis a sete anos, internadas na ala pediátrica do Hospital Escola de Medicina de Botucatu, com o diagnóstico de alguma patologia aguda e um período de internação não superior a 30 dias. A pesquisa compôs-se de dois grupos, divididos entre "tarde" e "noite". Foi aplicado o seguinte protocolo em cada grupo: uma coleta de saliva (com o Kit Salivette ${ }^{\circledR}$ - Sarstedt) e apresentação de uma escala de satisfação com desenhos de rostos, que ia de 1 a 7 , sendo 1 para muito triste e 7 para muito feliz. As crianças pintaram o desenho do rosto, escolhendo-o de acordo com o que elas estavam sentindo no momento. Logo após da realização da escala de satisfação, as crianças foram entretidas por uma hora e meia pelos "Doutores Palhaços", com brincadeiras, leitura de pequenas histórias, brincadeiras com balões e canções com instrumentos musicais. Após a diversão, uma nova amostra de saliva e nova pintura da escala de satisfação foram realizadas. Após as brincadeiras com os "Doutores Palhaços", o cortisol salivar reduziu-se nos dois grupos. A escala de satisfação foi significante no grupo da tarde, mas não no grupo da noite. Os autores concluíram que este estudo forneceu evidência fisiológica dos efeitos benéficos das atividades lúdicas dos "Doutores Palhaços" na ala da Pediatria. Por conseguinte, essas atividades devem ser mais estimuladas dentro de uma atmosfera hospitalar, uma vez que reduz um importante fator de estresse fisiológico em crianças hospitalizadas.

\subsection{Salivette $\AA$}

A coleta de saliva pode ser realizada em um tubo de plástico ou de 
vidro. Utilizando-se os tubos de vidro, elimina-se o risco de ligação do cortisol na superfície do dispositivo de armazenamento. Infelizmente, para o transporte e armazenamento num freezer, o vidro é desfavorável. Assim, tubos de plástico são, a princípio, mais adequados para as coletas de cortisol salivar. No entanto, ao utilizar dispositivos de plástico, deve garantir-se que estes não possuem nenhuma afinidade de ligação significativa com o cortisol (Kiess e Pfaeffle 2007, Kudielka et al. 2012)

A maioria dos dispositivos de coleta é composta de pastilhas absorventes, rolos de algodão ou esferas. Muitas vezes, o algodão é o material de escolha para a coleta da saliva, porque este material caracteriza-se por uma elevada capacidade absorvente, em comparação com fibras sintéticas. Existem vários dispositivos de coleta, disponíveis comercialmente, que podem ser utilizados. A maioria deles trabalha com um material absorvente, que é colocado na boca durante 1 a 5 minutos. Subsequentemente, o material embebido é armazenado em um recipiente fechado, para transporte e armazenamento até os testes laboratoriais (Kudielka et al. 2012).

Nos anos mais recentes, foram desenvolvidos dispositivos para coleta da saliva empregando-se, por exemplo, o Salivette ${ }^{\circledR}$ (Sarstedt, Alemanha) (Kiess e Pfaeffle 2007), que é o método mais comumente utilizado hoje em dia. Este kit é composto de um tubo para centrifugação, um recipiente suspenso, um rolete de algodão e uma tampa. No momento da coleta, o algodão é inserido na cavidade bucal e os participantes são instruídos a mastigá-lo ou mantê-lo embaixo da língua. A literatura apresenta recomendações diferentes para o tempo de manutenção do algodão na boca, para que efetivamente absorva a saliva: por cerca de 45 segundos, de acordo com Sarsted (2005); 1 minuto, conforme Aardal e Holm (1995), Carrion et al. (2002), Keller (2006), Curcio et al. (2013) e Nederhof et al. (2015) e 2 a 3 minutos, segundo Kiess et al. (1995), Tornhage (2002) e Lima (2014).

O Salivette $\AA$ é um dispositivo especialmente desenvolvido para mensuração do cortisol na saliva. A taxa de mensuração é 100\%, independentemente da concentração de cortisol, quantidade de saliva ou do método de análise utilizado. O Salivette ${ }^{\circledR}$ é projetado para mensurar valores precisos, a partir de pequenos volumes de amostras e níveis muito baixos de 
cortisol (Sarsted). Este dispositivo comercial é uma maneira comum e muito utilizada para obtenção de saliva para análise em adultos (Aardal e Holm 1995, Kirschbaum et al. 1996, Wust et al. 2000 , Vedhara et al. 2000, Lindauer et al. 2005, Gallagher et al. 2006, Keller 2006, Kanegane 2007, Roelofs et al. 2007, Ferreira 2011, Gassling et al. 2012, Henckens et al. 2012, Abu-Samak et al. 2014, Campos e David 2014, Lima 2014, Qi et al. 2016) e crianças (Tornhage 2002, Groschl et al. 2003, Rosmalen et al., 2005, Curcio et al. 2013, Gomes et al. 2015, Nederhof et al. 2015, Gomes et al. 2016, Saliba et al. 2016).

\subsubsection{O armazenamento da saliva}

A literatura tem os mais diferentes relatos sobre o armazenamento de amostra de saliva coletada para a mensuração do cortisol. Em vários estudos, os indivíduos são encarregados de recolher as amostras de saliva em casa. Portanto, as condições de armazenamento muitas vezes não são perfeitamente rastreáveis e o período de recolha de saliva nos estudos, frequentemente, demora vários meses ou anos até a conclusão (Kudielka et al. 2012). Pensando nisso, alguns estudos investigaram a estabilidade de cortisol salivar sob diferentes condições de armazenagem. Apesar de alguns estudos afirmarem que o descongelamento e congelamento não prejudicam a determinação dos níveis de cortisol (Clements e Parker 1984), alguns autores relataram que não há necessidade de refrigeração das amostras após a coleta e nem durante o transporte, pois o cortisol na saliva é extraordinariamente estável, podendo ficar preservado de sete dias (Chen et al.1992) a um mês ou mais, em temperatura ambiente (Kahn et al. 1988, Kalman e Grahn 2004). Kalman e Grahn (2004) alertam somente pelo cheiro desagradável que a saliva irá ficar, dentro de poucos dias e que, dado que os ciclos de congelamento e descongelamento repetidos não são um problema, os indivíduos podem armazenar as amostras em seu próprio freezer na primeira oportunidade ou no prazo de três dias, no máximo.

Groschl et al. (2001) investigaram a influência do armazenamento, em temperatura superior a $0^{\circ} \mathrm{C}$, na estabilidade do cortisol salivar. Foi 
observada uma diminuição significativa das concentrações de cortisol em amostras de saliva a partir do $5^{\circ}$ dia de armazenamento. Após 21 dias, a diminuição de cortisol na saliva foi de $62 \%$ à temperatura ambiente e $60 \%$ a $4^{\circ} \mathrm{C}$. Nas amostras centrifugadas, eles encontraram uma menor diminuição, acentuada de $22 \%$ após três semanas, em ambas as condições de armazenamento. O cortisol coletado pelo método do rolo de algodão (Kit Salivette®) possui a vantagem de uma longa estabilidade após a centrifugação; permanece sem alterações por três meses, quando armazenado a $5{ }^{\circ} \mathrm{C}$, ou até um ano, quando congelado de $-20^{\circ} \mathrm{C}$ a $-80^{\circ} \mathrm{C}$ (Groschl et al. 2001, Garde e Hansen 2005).

As formas mais indicadas pelos diferentes autores para armazenamento de cortisol salivar, no dia da coleta, são: congelamento a $-\mathbf{2 0}^{\circ} \mathrm{C}$ (Riad-Fahmy et al. 1982, Aardal e Holm 1995, Kiess et al. 1995, Kirschbaum et al. 1996, Ellenbogen et al. 2002, Lindauer et al. 2005, Amenábar 2006, Gallagher et al. 2006, Kanegane 2007, Roelofs et al., 2007, Silva et al. 2007, McCarthy et al. 2009, Gassling et al. 2012, Abu-Samak et al. 2014), $-\mathbf{- 2 5}^{\circ} \mathrm{C}$ (Henckens et al. 2012), $-\mathbf{- 7 0}^{\circ} \mathrm{C}$ (Morelius et al. 2004) ou $-\mathbf{8 0}^{\circ} \mathrm{C}$ (Gomes et al 2015, Gomes et al. 2016, Qi et al. 2016).

Alguns autores afirmam que a amostra de saliva coletada deve ser armazenada em isopor com gelo, até que possa ser levado para o congelamento em um freezer (Keller 2006, Kanegane 2007) e que o descongelamento e congelamento não prejudicam a determinação dos níveis de cortisol (Clements e Parker 1984). 

3 Objettivo

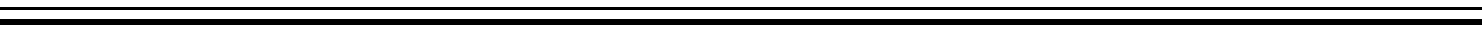





\section{Objetivo}

3.1 Objetivo Geral

- Verificar a possível correlação entre o nível de cortisol salivar e a atenção auditiva sustentada em crianças com fissura labiopalatina.

3.2 Objetivos específicos

- Verificar o nível de cortisol dos indivíduos estudados em relação à idade, sexo e o número de atendimentos realizados no dia;

- Verificar a possível correlação entre o nível de cortisol e o número de atendimentos realizados no dia;

- Verificar o desempenho dos indivíduos no Teste de Habilidade de Atenção Auditiva Sustentada;

- Verificar a possível correlação entre os sexos e entre as idades no desempenho do Teste de Habilidade de Atenção Auditiva Sustentada. 

4 Chaterial e Chétodos 



\section{Material e MÉtodo}

Este estudo foi aprovado pela Comissão de Ética em Pesquisa do HRAC, conforme ofício 1.163.126. Seguindo os critérios de inclusão, participaram desta pesquisa 69 crianças voluntárias, brasileiras, com fissura labiopalatina (31 do gênero feminino e 38 do masculino), com idade média de 8 anos e 5 meses.

\subsection{Casuística}

Para este estudo prospectivo foram selecionadas, aleatoriamente, 483 crianças com qualquer tipo de fissura labiopalatina com envolvimento do palato (pré+pós forame, transforame e pós-forame) (Spina et al. 1972), com ou sem bandeleta de Simonart, sem síndromes associadas, de ambos os sexos, que estavam em rotina hospitalar do HRAC. Para todas elas, foi agendado um horário especial para a realização dos exames propostos, em meio a outras consultas. Dos 414 pacientes que não participaram da pesquisa, 250 apresentavam impedimento para realização da avaliação audiológica (presença de cerúmen, limiares auditivos acima de $15 \mathrm{~dB}$, presença de tubo de ventilação, curva timpânica sem pico de máxima compliância, membrana timpânica perfurada ou uso de medicamentos controlados); e, 164 não comparecem ao horário agendado. Dos 69 participantes da pesquisa, 49 apresentavam fissura transforame incisivo, sete fissura pós-forame incisivo e 13, fissura pré + pós forame incisivo.

Como critério de inclusão na pesquisa, as crianças deveriam estar na faixa etária de seis a 11 anos, apresentar ausência de queixa auditiva, apresentar audição dentro dos padrões de normalidade esperado para a idade, capacidade de compreender o teste a ser aplicado, ausência de queixa e/ou afecção das vias aéreas superiores no dia do exame, inexistência de histórico de queixa de desatenção e ter o Termo de Consentimento Livre e Esclarecido assinado pelos responsáveis das crianças participantes do estudo. Os critérios 
de exclusão foram: pacientes que tivessem se alimentado (principais refeições) até uma hora antes do teste e crianças que houvessem feito uso de corticosteroides orais em até um mês antes da coleta de saliva.

Para a comprovação de que as crianças sem queixa auditiva não apresentavam qualquer alteração audiológica, após a inspeção visual do meato acústico externo, uma fonoaudióloga, colaboradora na pesquisa, realizou uma triagem auditiva, na qual pesquisou os limiares aéreos nas frequências de 500 $\mathrm{Hz}, 1000 \mathrm{~Hz}$ e $2000 \mathrm{~Hz}$, bem como a timpanometria. Considerou-se como padrão de normalidade os limiares tonais aéreos de até 15 dBNA e curva timpanométrica tipo A (Jerger et al. 1970). A inspeção visual do meato acústico externo foi feita com um otoscópio da marca Heine, com o objetivo de verificar a presença de algum impedimento para realização da avaliação auditiva, tais como excesso de cerúmen ou presença de corpo estranho. Ressalte-se que, durante a inspeção visual do meato acústico externo, ao ser observada alguma alteração que impedisse a realização da avaliação audiológica, a criança era encaminhada para um otorrinolaringologista para procedimentos necessários.

Para obter informações sobre a saúde e a habilidade de atenção auditiva, aplicou-se um questionário (Anexo A) constituído de quatro partes:

- Parte I - Dados da criança (nome, gênero, idade, endereço, grau de escolaridade), assim como o nível de instrução dos pais;

- Parte II - Saúde auditiva (história positiva de perda auditiva e de infecções otológicas, e se presente, a sua lateralidade);

- Parte III - Atenção da criança (quanto a não prestar atenção às instruções mais de $50 \%$ das vezes, a necessitar que as instruções Ihe fossem repetidas frequentemente, a perguntar o que the foi dito, constantemente, dizendo "an?, o quê?", apresentar atenção curta, não prestar atenção ao som, apresentar comportamento de "sonhar acordado"; presença de diagnóstico de transtorno de déficit de atenção e hiperatividade (TDAH) e/ou distúrbios da comunicação e uso de medicamento para TDAH); e, 
- Parte IV - Dados Escolares (questões sobre desempenho escolar, histórico de repetência, problemas comportamentais, desatenção em sala de aula e queixas do professor).

A Tabela 1 apresenta a distribuição geral das crianças participantes da pesquisa.

Tabela 1 - Distribuição das crianças segundo a idade, sexo e tipo de fissura labiopalatina

\begin{tabular}{|c|c|c|c|c|c|c|c|}
\hline \multirow{3}{*}{$\begin{array}{l}\text { Idade } \\
\text { (anos) }\end{array}$} & \multicolumn{6}{|c|}{ Tipos de Fissura } & \multirow{3}{*}{ Total } \\
\hline & \multicolumn{2}{|c|}{ Transforame } & \multicolumn{2}{|c|}{ Pós-forame } & \multicolumn{2}{|c|}{ Pré+Pós Forame } & \\
\hline & Masculino & Feminino & Masculino & Feminino & Masculino & Feminino & \\
\hline 6 & 6 & 4 & 1 & 1 & 0 & 1 & 13 \\
\hline 7 & 2 & 0 & 0 & 0 & 1 & 0 & 3 \\
\hline 8 & 6 & 1 & 0 & 3 & 3 & 0 & 13 \\
\hline 9 & 5 & 6 & 0 & 1 & 3 & 0 & 15 \\
\hline 10 & 7 & 10 & 0 & 1 & 3 & 1 & 22 \\
\hline 11 & 1 & 1 & 0 & 0 & 1 & 0 & 3 \\
\hline Total & 27 & 22 & 1 & 6 & 11 & 2 & 69 \\
\hline
\end{tabular}

Todos os procedimentos audiológicos foram acompanhados pela pesquisadora e realizados por uma fonoaudióloga, sob a supervisão da orientadora.

\subsection{Procedimentos}

Todas as crianças que seguiram os critérios de inclusão foram submetidas, primeiramente, à coleta de saliva e, em seguida, ao Teste de Habilidade de Atenção Auditiva Sustentada (THAAS) de Feniman et al. (2007b) (Anexo B).

\subsubsection{Coleta de saliva}

As amostras de saliva foram obtidas por uma cirurgiã-dentista, 
colaboradora na pesquisa, por meio do Salivette® (Sarstedt, Rommelsdorf, Germany) e de forma padronizada, ou seja, sempre no período da tarde (entre 13h30min e 17h00), quando os níveis de cortisol estão relativamente estáveis (Kiess e Pfaeffle 2007, Nieman et al. 2008, McCarthy et al. 2009, Henckens et al. 2012). Para as crianças que haviam ingerido pequenas quantidades de alimentos ou bebidas em até 30 minutos antes da coleta, foi solicitado que realizassem um bochecho com água e aguardassem de três a cinco minutos.

Estabeleceu-se como protocolo de coleta:

1) explicar para os responsáveis e para a criança o procedimento da coleta de saliva;

2) abrir a tampa do Salivette® e retirar um rolo de algodão do interior do mesmo;

3) inserir o rolo de algodão no interior da boca da criança, mais precisamente na região sublingual;

4) pedir para que a criança aguardasse de dois a três minutos com o algodão dentro da boca, sem necessidade de qualquer simulação mastigatória;

5) retirar o algodão de dentro da boca da criança;

6) guardar o algodão no dispositivo plástico e tampá-lo;

7) armazenar as amostras em isopor com gelo e levar o mais rápido possível para armazenamento no Laboratório, a $-20^{\circ} \mathrm{C}$.

O cortisol presente nas amostras de saliva foi mensurado por um kit imunoensaio enzimático (Salimetrics, Stage College, PA, USA), no Laboratório de Farmacologia e Genética da Faculdade de Odontologia de Bauru (FOB USP). Os níveis de cortisol foram determinados de acordo com as instruções do fabricante, seguindo a curva padrão. Os limites de detecção para a faixa etária estudada nesta pesquisa variam entre "sem valor mínimo a 0,215 $\mu \mathrm{g} / \mathrm{dL}$ ). 


\subsubsection{Teste de Habilidade de Atenção Auditiva Sustentada (THAAS)}

Logo após a coleta de saliva, aplicou-se o Teste de Habilidade de Atenção Auditiva Sustentada (THAAS), um método de informação objetiva para descrever o comportamento de atenção auditiva sustentada em crianças. Esse teste é utilizado para avaliar a atenção auditiva, verificando a habilidade da criança em escutar estímulos auditivos durante um período de tempo prolongado e de responder somente para um estímulo específico. O THAAS é fundamentado no teste de desempenho contínuo. Envolve, portanto, uma tarefa de vigilância auditiva, evidenciada pelas respostas corretas para o solicitado, e mede a atenção sustentada, indicada pela habilidade da criança em manter a atenção e concentração na tarefa, por um período de tempo prolongado.

O THAAS consiste na apresentação de uma lista de 21 palavras monossilábicas, gravadas em voz masculina e apresentadas na proporção de uma palavra por segundo, as quais são repetidas e rearranjadas aleatoriamente, formando uma lista de 100 palavras, incluindo as 20 ocorrências da palavra-alvo "não", dispostas de maneira aleatória. Esta lista (gravada em $C D$ ) foi apresentada seis vezes, sem interrupção. O THAAS foi realizado em cabina acústica, utilizando-se fones, com auxílio de um $C D$ player acoplado a um audiômetro de dois canais, a uma intensidade de $50 \mathrm{dBNS}$, considerada a média dos limiares aéreos auditivos de 500, 1000 e $2000 \mathrm{~Hz}$ para cada orelha, apresentado de maneira binaural e diótica e teve uma duração média de 11 minutos.

A avaliadora instruiu oralmente a criança para que ouvisse uma lista de palavras e que levantasse a mão toda vez que escutasse a palavra "não". Anteriormente à primeira apresentação da lista de 100 palavras do THAAS, para que a criança compreendesse perfeitamente o que deveria fazer, foi apresentada a ela uma gravação com 50 palavras monossilábicas, pronunciadas sem interrupção, sendo 10 delas a palavra "não". Somente após a criança entender a tarefa, o teste foi iniciado. As respostas das crianças foram marcadas com um xis $(\mathrm{X})$ no protocolo de resposta (lista de 
monossílabos), em frente a cada palavra do teste para a qual a criança levantou a mão.

O desempenho no THAAS é dado pela pontuação total de erros ou decréscimo de vigilância. Na pontuação total de erros são considerados dois tipos de erros: desatenção e impulsividade. Denominou-se desatenção quando a criança não levantava a mão em resposta à palavra-alvo "não", antes da apresentação da palavra seguinte; e impulsividade, quando a criança levantava a mão para outra palavra, em vez da palavra "não". A contagem do número de erros de desatenção, acrescida do número de erros de impulsividade permitiu obter a pontuação total de erros no THAAS. O decréscimo de vigilância é dado pela diferença obtida entre o número de respostas corretas obtida na $1^{\text {a }}$ apresentação da lista de 100 palavras e o número de respostas corretas obtida na 6ª apresentação desta lista.

\subsubsection{Análise estatística}

Tendo em vista o objetivo proposto e seguindo a metodologia, os níveis de cortisol foram obtidos para todas as crianças do estudo e relacionados quanto ao sexo, à idade e ao efeito sexo e idade, bem como ao número de atendimentos (consultas) realizado no dia da coleta. Para fins de análise, os pacientes foram divididos, com base no número de atendimentos, isto é, de acordo com o momento do dia em que foi feita a coleta de saliva e realizado o teste THAAS. Dezessete crianças já tinham sido submetidas a um ou dois atendimentos no dia; 39 já haviam passado pelo terceiro ou quarto atendimento do dia; e, 13 crianças após o quinto ou sexto atendimento do dia. O desempenho das crianças no THAAS foi obtido e analisado quanto à idade, ao sexo, bem como, a sua correlação com o nível de cortisol.

A correlação do nível de cortisol salivar com a atenção auditiva e a correlação do número de atendimentos com o nível de cortisol foi avaliada pelo coeficiente de correlação de Spearman. Para verificar o desempenho das crianças no THAAS, foi utilizado o Teste "t". O nível mínimo de significância usado foi de $1 \%(p<0,01)$. 
5 Q esultados 



\section{Resultados}

\subsection{Nível de cortisol salivar}

Os valores de cortisol encontrados variaram entre 0,01 e $0,19 \mu \mathrm{l} / \mathrm{dL}$, resultando em uma média total de $0,05 \mu \mathrm{l} / \mathrm{dL}$.

Os indivíduos do sexo masculino apresentaram média superior aos indivíduos do sexo feminino, com resultados de $0,053 \mu \mathrm{l} / \mathrm{dL}(\mathrm{dp}=0,037)$ e 0,051 $\mu \mathrm{l} / \mathrm{dL}(\mathrm{dp}=0,042)$, respectivamente. Não houve diferença estatística do nível de cortisol entre os grupos $(p=0,82)$. A Tabela 2 descreve a média de cortisol encontrada em cada faixa etária dos participantes da pesquisa.

Tabela 2 - Média do cortisol salivar, segundo a idade

\begin{tabular}{cccc}
\hline Idade (anos) & $\mathbf{N}$ & Cortisol $(\mu \mathrm{l} / \mathrm{dL})$ & Desvio padrão \\
\hline 6 & 13 & 0,048 & 0,042 \\
7 & 3 & 0,084 & 0,099 \\
8 & 13 & 0,060 & 0,039 \\
9 & 15 & 0,055 & 0,042 \\
10 & 22 & 0,047 & 0,026 \\
11 & 3 & 0,028 & 0,004 \\
\hline
\end{tabular}

A Tabela 3 apresenta as médias encontradas do cortisol salivar, segundo o sexo e idade.

Tabela 3 - Média do cortisol salivar, segundo o sexo e idade

\begin{tabular}{ccccc}
\hline \multirow{2}{*}{ Idade (anos) } & \multicolumn{2}{c}{ Masculino } & \multicolumn{2}{c}{ Feminino } \\
\cline { 2 - 5 } \cline { 3 - 5 } & Cortisol $(\boldsymbol{\mu l} / \mathbf{d L})$ & Desvio Padrão & Cortisol $(\boldsymbol{\mu l} / \mathbf{d L})$ & Desvio Padrão \\
\hline $\mathbf{6}$ & 0,0594 & 0,0558 & 0,0366 & 0,0172 \\
$\mathbf{7}$ & 0,0274 & 0,0021 & 0,1992 & $*$ \\
$\mathbf{8}$ & 0,0557 & 0,0364 & 0,0713 & 0,0497 \\
$\mathbf{9}$ & 0,0627 & 0,0389 & 0,0480 & 0,0471 \\
$\mathbf{1 0}$ & 0,0511 & 0,0293 & 0,0437 & 0,0249 \\
$\mathbf{1 1}$ & 0,0269 & 0,0033 & 0,0331 & $*$ \\
\hline
\end{tabular}

*Apenas um indivíduo nesta faixa etária e gênero 
A Tabela 4 apresenta os valores de cortisol encontrados com base no número de atendimentos do dia, até o momento da realização do teste.

Tabela 4 - Valores encontrados de cortisol, segundo o número de atendimento

\begin{tabular}{cccc}
\hline Atendimentos & N & Cortisol & Desvio padrão \\
\hline Um ou dois & 17 & 0,048 & 0,034 \\
Três ou quatro & 39 & 0,055 & 0,039 \\
Cinco ou seis & 13 & 0,050 & 0,047 \\
\hline
\end{tabular}

A Tabela 5 apresenta por idade a correlação existente entre número de atendimentos e o nível de cortisol encontrado.

Tabela 5 - Coeficiente de correlação entre o número de atendimentos pelos quais a criança passou e o nível de cortisol

\begin{tabular}{|c|c|c|c|}
\hline & $\begin{array}{l}\text { Idade } \\
\text { (anos) }\end{array}$ & Cortisol & Número de Atendimentos \\
\hline \multirow{6}{*}{$\begin{array}{l}\bar{o} \\
\stackrel{o}{t} \\
\bar{\partial}\end{array}$} & 6 & 1,000 & 0,054 \\
\hline & 7 & 1,000 & $1,000^{\star}$ \\
\hline & 8 & 1,000 & $-0,121$ \\
\hline & 9 & 1,000 & $-0,153$ \\
\hline & 10 & 1,000 & $-0,107$ \\
\hline & 11 & 1,000 & $-0,500$ \\
\hline \multirow{6}{*}{ 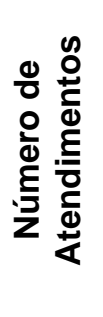 } & 6 & 0,054 & 1,000 \\
\hline & 7 & $1,000^{*}$ & 1,000 \\
\hline & 8 & $-0,121$ & 1,000 \\
\hline & 9 & $-0,153$ & 1,000 \\
\hline & 10 & $-0,107$ & 1,000 \\
\hline & 11 & $-0,500$ & 1,000 \\
\hline
\end{tabular}

$\approx \bar{p} \leq 0,01$

\subsection{Teste de Habilidade de Atenção Auditiva Sustentada}

Os resultados obtidos no THAAS em crianças com fissura labiopalatina estão descritos nas Tabelas 6, 7 e 8. 
A Tabela 6 apresenta os valores médios obtidos com o desempenho dos participantes da pesquisa no Teste de Habilidade de Atenção Auditiva Sustentada realizado.

Tabela 6 - Valores médios e desvio-padrão(DP) do THAAS por idade

\begin{tabular}{|c|c|c|c|c|c|c|c|c|}
\hline \multirow{2}{*}{$\begin{array}{l}\text { Idade } \\
\text { (anos) }\end{array}$} & \multicolumn{2}{|c|}{ Desatenção } & \multicolumn{2}{|c|}{ Impulsividade } & \multicolumn{2}{|c|}{$\begin{array}{c}\text { Pontuação Total } \\
\text { de Erros }\end{array}$} & \multicolumn{2}{|c|}{$\begin{array}{l}\text { Decréscimo de } \\
\text { Vigilância }\end{array}$} \\
\hline & Média & DP & Média & DP & Média & DP & Média & DP \\
\hline 6 & 16,00 & 12,72 & 6,31 & 4,05 & 22,31 & 12,06 & 2,15 & 1,90 \\
\hline 7 & 25,00 & 19,7 & 3,66 & 0,57 & 28,66 & 19,1 & 1,33 & 2,52 \\
\hline 8 & 9,85 & 7,17 & 5,92 & 5,44 & 15,77 & 10,6 & 1,92 & 2,01 \\
\hline 9 & 8,87 & 8,60 & 3,86 & 2,32 & 12,73 & 9,06 & 0,86 & 1,95 \\
\hline 10 & 6,36 & 7,05 & 3,13 & 2,69 & 9,49 & 8,07 & 0,77 & 1,85 \\
\hline 11 & 5,67 & 5,51 & 6,00 & 2,65 & 11,67 & 8,08 & 0,66 & 0,57 \\
\hline
\end{tabular}

Tabela 7 - Valores médios dos erros (desatenção, impulsividade e pontuação total) e decréscimo de vigilância nas faixas etárias segundo os sexos

\begin{tabular}{|c|c|c|c|c|c|c|c|c|c|c|c|c|c|c|c|c|}
\hline \multirow{2}{*}{$\begin{array}{c}\text { Ida- } \\
\text { de }\end{array}$} & \multicolumn{4}{|c|}{ Desatenção } & \multicolumn{4}{|c|}{ Impulsividade } & \multicolumn{4}{|c|}{$\begin{array}{c}\text { Pontuação Total } \\
\text { de Erros }\end{array}$} & \multicolumn{4}{|c|}{$\begin{array}{l}\text { Decréscimo de } \\
\text { Vigilância }\end{array}$} \\
\hline & M & DP & $\mathbf{F}$ & DP & M & DP & $\mathbf{F}$ & DP & M & DP & $\mathbf{F}$ & DP & M & DP & $\mathbf{F}$ & DP \\
\hline 6 & 14,71 & 9,76 & 17,50 & 16,40 & 8 & 4,36 & 4,3 & 2,80 & 22,71 & 8,54 & 21,83 & 16,17 & 1,42 & 1,27 & 3 & 2,28 \\
\hline 7 & 28 & 26,9 & 19 & * & 3,5 & 0,70 & 4 & * & 31,5 & 26,2 & 23 & * & 0 & 1,41 & 4 & * \\
\hline 8 & 10,66 & 6,96 & 8 & 8,37 & 7,22 & 6,04 & 3 & 2,16 & 17,89 & 11,30 & 11 & 8,41 & 1,6 & 1,58 & 2,5 & 3 \\
\hline 9 & 8,75 & 11,27 & 9 & 4,93 & 4,12 & 2,35 & 3,57 & 2,44 & 12,88 & 11,21 & 12,57 & 6,70 & 0,62 & 2,13 & 1,14 & 1,86 \\
\hline 10 & 7,2 & 8,87 & 5,6 & 5,42 & 3,9 & 2,64 & 2,5 & 2,68 & 11,10 & 10,08 & 8,17 & 6,07 & 1,3 & 2,26 & 0,33 & 1,37 \\
\hline 11 & 2,5 & 0,70 & 12 & - & 4,5 & 0,70 & 9 & * & 7 & 0,00 & 21 & * & 0,5 & 0,70 & 1 & * \\
\hline
\end{tabular}

Tabela 8 - Coeficiente de correlação entre os sexos no desempenho no THAAS

\begin{tabular}{|c|c|c|c|c|c|c|c|c|}
\hline \multirow[b]{2}{*}{ Sexo } & \multicolumn{2}{|c|}{ Desatenção } & \multicolumn{2}{|c|}{ Impulsividade } & \multicolumn{2}{|c|}{$\begin{array}{l}\text { Pontuação Total } \\
\text { de Erros }\end{array}$} & \multicolumn{2}{|c|}{$\begin{array}{l}\text { Decréscimo de } \\
\text { Vigilância }\end{array}$} \\
\hline & $\mathbf{M}$ & $\mathbf{F}$ & $M$ & $\mathbf{F}$ & $M$ & $\mathbf{F}$ & $M$ & $\mathbf{F}$ \\
\hline$M$ & 1,000 & 0,7270 & 1,000 & $-0,1019$ & 1,000 & 0,4928 & 1,000 & $-0,2181$ \\
\hline $\mathbf{F}$ & 0,7270 & 1,000 & $-0,1019$ & 1,000 & 0,4928 & 1,000 & $-0,2181$ & 1,000 \\
\hline
\end{tabular}


Tabela 9 - Coeficiente de correlação entre o desempenho no THAAS e o nível de cortisol

\begin{tabular}{|c|c|c|c|c|c|c|}
\hline & $\begin{array}{l}\text { Idade } \\
\text { (anos) }\end{array}$ & Desatenção & $\begin{array}{l}\text { Impulsi- } \\
\text { vidade }\end{array}$ & $\begin{array}{c}\text { Pontuação } \\
\text { Total de } \\
\text { Erros }\end{array}$ & $\begin{array}{c}\text { Decréscimo } \\
\text { de } \\
\text { Vigilância }\end{array}$ & Cortisol \\
\hline \multirow{6}{*}{ 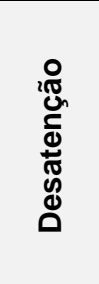 } & 6 & 1,000 & $-0,312$ & $0,952^{\star \star}$ & $0,649^{*}$ & 0,413 \\
\hline & 7 & 1,000 & $-0,866$ & $1,000^{\star \star}$ & $-0,500$ & $-0,500$ \\
\hline & 8 & 1,000 & 0,501 & $0,920^{\star \star}$ & $0,827^{\star \star}$ & 0,235 \\
\hline & 9 & 1,000 & 0,200 & $0,942^{\star \star}$ & 0,492 & $-0,528^{*}$ \\
\hline & 10 & 1,000 & 0,194 & $0,856^{\star \star}$ & 0,273 & $-0,114$ \\
\hline & 11 & 1,000 & 0,500 & 0,866 & 0,000 & $1,000^{\star \star}$ \\
\hline \multirow{6}{*}{$\begin{array}{l}\frac{0}{0} \\
\frac{\pi}{0} \\
\frac{0}{2} \\
\frac{0}{3} \\
\text { 트 }\end{array}$} & 6 & $-0,312$ & 1,000 & $-0,75$ & $-0,322$ & 0,110 \\
\hline & 7 & $-0,866$ & 1,000 & $-0,866$ & 0,866 & 0,866 \\
\hline & 8 & 0,501 & 1,000 & $0,731^{\star \star}$ & 0,221 & 0,025 \\
\hline & 9 & 0,200 & 1,000 & 0,432 & 0,148 & 0,129 \\
\hline & 10 & 0,194 & 1,000 & $0,610^{\star *}$ & 0,009 & $-0,222$ \\
\hline & 11 & 0,500 & 1,000 & 0,866 & 0,866 & 0,500 \\
\hline \multirow{6}{*}{ 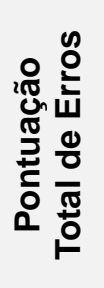 } & 6 & $0,952^{\star \star}$ & $-0,075$ & 1,000 & $0,564^{*}$ & 0,370 \\
\hline & 7 & $1,000^{\star \star}$ & $-0,866$ & 1,000 & $-0,500$ & $-0,500$ \\
\hline & 8 & $0,920^{\star *}$ & $0,731^{\star \star}$ & 1,000 & $0,719^{\star \star *}$ & 0,258 \\
\hline & 9 & $0,942^{* *}$ & 0,432 & 1,000 & $0,581^{*}$ & $-0,476$ \\
\hline & 10 & $0,856^{\star *}$ & $0,610^{\star *}$ & 1,000 & 0,232 & $-0,193$ \\
\hline & 11 & 0,866 & 0,866 & 1,000 & 0,500 & 0,866 \\
\hline \multirow{6}{*}{ 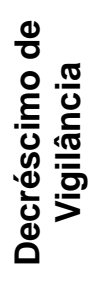 } & 6 & $0,649^{\star}$ & $-0,322$ & $0,564^{\star}$ & 1,000 & $-0,008$ \\
\hline & 7 & $-0,500$ & 0,866 & $-0,500$ & 1,000 & $1000^{\star *}$ \\
\hline & 8 & $0,827^{\star *}$ & 0,221 & $0,719^{\star *}$ & 1,000 & 0,506 \\
\hline & 9 & 0,492 & 0,148 & $0,581^{*}$ & 1,000 & $-0,233$ \\
\hline & 10 & 0,273 & 0,009 & 0,292 & 1,000 & 0,106 \\
\hline & 11 & 0,000 & 0,866 & 0,500 & 1,000 & 0,000 \\
\hline \multirow{6}{*}{ 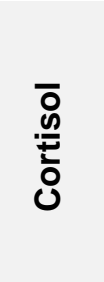 } & 6 & 0,413 & 0,110 & 0,370 & $-0,008$ & 1,000 \\
\hline & 7 & $-0,500$ & 0,866 & $-0,500$ & $1,000^{\star \star}$ & 1,000 \\
\hline & 8 & 0,235 & 0,025 & 0,258 & 0,506 & 1,000 \\
\hline & 9 & $-0,528^{\star}$ & 0,129 & $-0,476$ & $-0,233$ & 1,000 \\
\hline & 10 & $-0,114$ & $-0,222$ & $-0,193$ & 0,106 & 1,000 \\
\hline & 11 & $1,000^{* \star}$ & 0,500 & 0,866 & 0,000 & 1,000 \\
\hline
\end{tabular}





\section{Discussão}

\subsection{Cortisol salivar}

A dosagem do cortisol por meio da saliva vem sendo amplamente utilizada em crianças e adultos. O método de coleta, com o auxílio do dispositivo Salivette ${ }^{\circledR}$ e o método de análise laboratorial, foi adotado em estudos anteriores (Aardal e Holm 1995, Kirschbaum et al. 1996, Vedhara et al. 2000, Wust et al. 2000 b Ellenbogen et al. 2002, Tornhage 2002, Groschl et al. 2003, Lindauer et al. 2005, Rosmalen et al. 2005, Gallagher et al. 2006, Keller 2006, Kanegane 2007, Roelofs et al. 2007, Ferreira 2011, Henckens et al. 2012, Curcio et al. 2013, Abu-Samak et al. 2014, Campos e David 2014, Lima 2014, Gomes et al. 2015, Nederhof et al. 2015, Qi et al. 2016, Saliba et al. 2016).

Feita por meio de imunoensaio, a dosagem de cortisol é considerada altamente sensível e específica, além de apresentar vantagens como possibilitar a realização da análise do cortisol com pequenos volumes de saliva. Neste trabalho, foram necessários $25 \mu \mathrm{g}$ de saliva para efetuar a análise. Outros autores indicam a mesma quantidade de saliva (Castro e Moreira 2003, Kalman e Grahn 2004) ou até realizaram pesquisas com uma quantidade ainda menor (Shimada et al. 1995, Morelius et al. 2004).

A forma de armazenamento, seguida de acordo com as instruções do fabricante, também foi a mesma utilizada por vários autores (Riad-Fahmy et al. 1982, Aardal e Holm 1995, Kiess et al. 1995, Kirschbaum et al. 1996, Ellenbogen et al. 2002, Lindauer et al. 2005, Amenábar 2006, Gallagher et al. 2006, Kanegane 2007, Roelofs et al. 2007, Silva et al. 2007, McCarthy et al. 2009, Abu-Samak et al. 2014).

Para avaliar o nível de cortisol salivar em crianças, esta pesquisa utilizou o $\mu \mathrm{g} / \mathrm{dL}$, que é a unidade de medida utilizada pelo fabricante, embora existam pesquisas que utilizam o $\mathrm{nmol} / \mathrm{L}(1 \mu \mathrm{g} / \mathrm{dL}$ equivale a $27,59 \mathrm{nmol} / \mathrm{L})$ (Salimetrics 2016).

O kit imunoensaio enzimático utilizado nesta pesquisa tem sensibilidade para detectar níveis de cortisol entre 0,007 e 3,000 $\mu \mathrm{g} / \mathrm{dL}$. A 
Figura 1 apresenta valores comuns de níveis de cortisol encontrados em pesquisas (Salimetrics 2016).

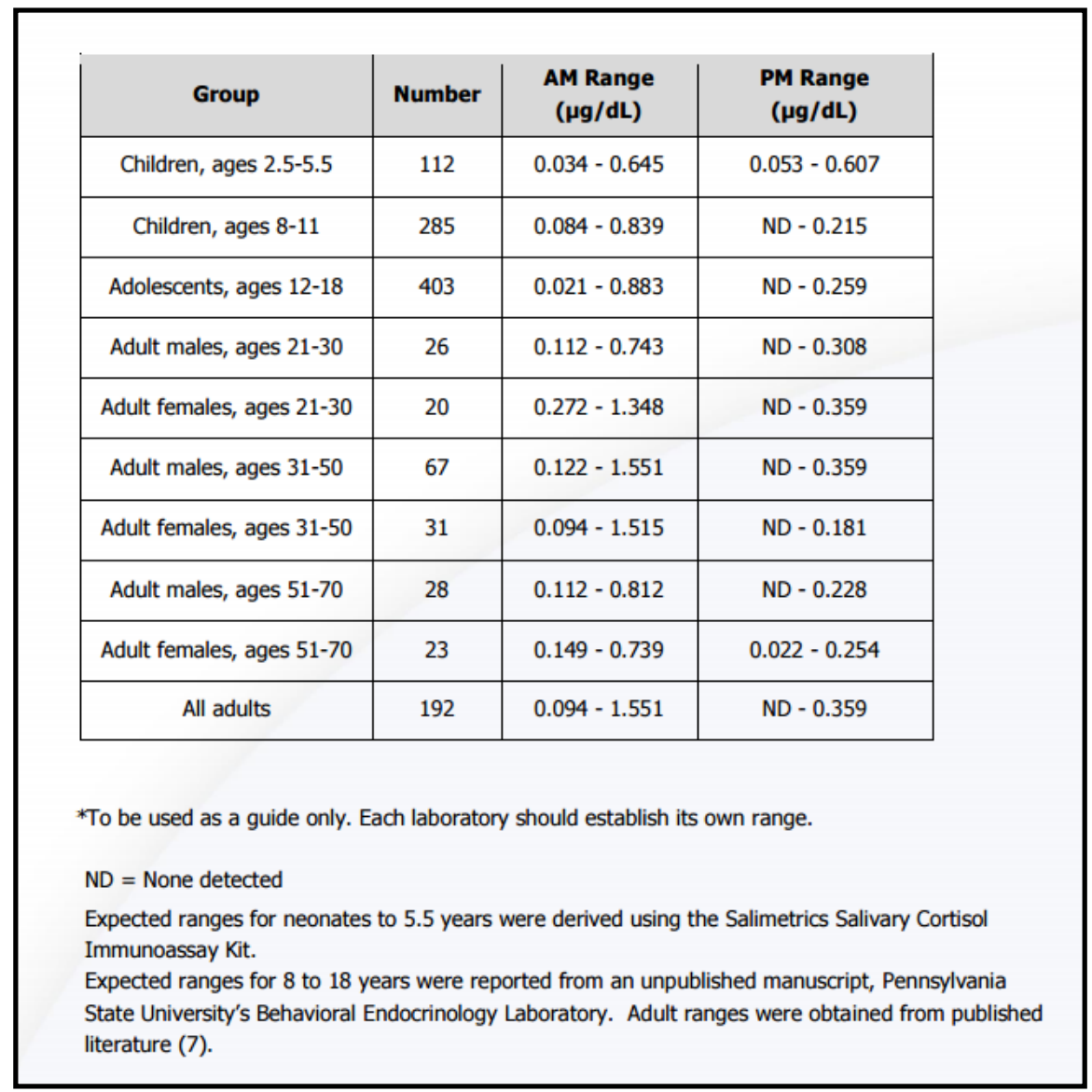

Fonte: Salimetrics (2016)

Figura 1 - Exemplos fornecidos pelo fabricante de níveis esperados de cortisol salivar, nas diferentes idades

Uma vez que a sensibilidade dos ensaios difere consideravelmente, é importante que os métodos de análise sejam usados separadamente, a cada pesquisa (Kiess e Pfaeffle 2007), o que dificulta discutir e comparar resultados dos níveis de cortisol entre ensaios distintos. Embora alguns artigos estabeleçam valores de referência, estes divergem bastante entre si. Por exemplo, as concentrações matinais de cortisol na saliva, relatadas por Silva et al. (2007), para crianças de 45 dias a três meses, correspondem, em média, a $557,86 \mathrm{nmol} / \mathrm{L}$ e variam entre 76,88 e 1.620,08 nmol/l. Kiess et al. (1995), entretanto, referem valores que variam de $4,3 \mathrm{nmol} / \mathrm{L}$ a $81,3 \mathrm{nmol} / \mathrm{L}$ para a 
mesma faixa etária. Rosmalen et al. (2005) relatam valores que variavam de 1,90 a 16,02 nmol/L para crianças de 10 a 12 anos e Tornhage e Alfven (2006) encontraram níveis matinais de $8,8 \mathrm{nmol} / \mathrm{L}$ em crianças de seis a 15 anos.

Schmidt (1997) destaca que, embora os valores basais não estejam bem estabelecidos, isso não impede o uso de cortisol salivar em pesquisa com crianças, pois o próprio indivíduo atua como controle em situações experimentais, podendo ser ele mesmo o melhor valor de referência.

A necessidade de um constante acompanhamento e atendimentos regulares por diversas especialidades em pacientes com fissura labiopalatina pode gerar certa ansiedade, principalmente nas crianças. De acordo com Curcio et al. (2013), um simples exame clínico pode ser a causa de significante elevação dos níveis de cortisol salivar. Apenas um artigo, envolvendo pacientes com fissura labiopalatina e cortisol, foi encontrado na literatura e este era com adultos (Gassling et al. 2012).

Dentre os pacientes que se encaixavam nos fatores de inclusão e que participaram desta pesquisa, uma criança foi excluída da amostra, totalizando 69 crianças. O seu nível de cortisol estava 14 vezes maior que a média $(0,70 \mu \mathrm{l} / \mathrm{L})$, justificado pelo seu comportamento, que se apresentava com choro intenso e verbalizando estar com muito medo. Muito embora tenha sido dada toda a orientação à criança, por desconhecimento do que iria ser realizado, a criança provavelmente supôs que seria submetida a algum procedimento dentário, uma vez que o local de realização da pesquisa foi o setor odontológico. Além disso, o período anterior a uma consulta odontológica pode gerar maior ansiedade/estresse entre crianças do que a própria consulta (Curcio et al. 2013).

Apesar da média de cortisol salivar ser ligeiramente maior entre os meninos e as medidas individuais de cortisol se mostrarem mais altas nas meninas, a ausência de significância estatística $(p=0,82 p<0,05)$ encontrada nos níveis de cortisol entre meninos e meninas (Tabela 2) corrobora os achados de McCarthy et al. (2009) e Curcio et al. (2013), que também não encontraram diferenças significativas nos níveis de cortisol entre os resultados obtidos com crianças de ambos os sexos. Não foram encontrados trabalhos 
que relataram diferenças significativas nos níveis de cortisol entre os sexos, na literatura consultada.

Gomes et al. (2015) utilizaram um kit imunoensaio enzimático (Salimetrics, Stage College, PA, USA) semelhante ao desta pesquisa, em estudo realizado com crianças de dois a cinco anos, e encontraram médias entre $0,25 \mu \mathrm{g} / \mathrm{dL}$ a $0,27 \mu \mathrm{g} / \mathrm{dL}$ de cortisol, em amostras de saliva coletadas alguns minutos antes da realização de um procedimento odontológico. Das cinco coletas de saliva efetuadas na pesquisa, a maior média de cortisol salivar $(1,05 \mu \mathrm{g} / \mathrm{dL})$ foi observada na amostra coletada após 25 minutos da anestesia aplicada para a realização do procedimento odontológico. Estes dados corroboram os de McCarthy et al. (2009), que referiram que os níveis de cortisol atingem seu pico em 20 a 30 minutos após o estímulo estressor. Gomes et al. (2016) também utilizaram um kit imunoensaio enzimático, idêntico ao desta pesquisa, em um estudo com crianças de dois a cinco anos e obtiveram médias de cortisol salivar que variaram de $0,12 \mu \mathrm{g} / \mathrm{dL}$ a 0,24 $\mu \mathrm{g} / \mathrm{dL}$.

As médias de cortisol encontradas nos trabalhos de Gomes et al. (2015) e Gomes et al. (2016) estão bem acima das médias encontradas nesta pesquisa, que foi de 0,05 $\mathrm{mg} / \mathrm{dL}$ entre crianças de seis a 11 anos (Tabela 2). Apesar da diferença encontrada, os referidos trabalhos demonstram resultados bem mais elevados em comparação com os parâmetros definidos para a idade, conforme o fabricante. Os resultados do cortisol salivar desta pesquisa se apresentaram dentro dos parâmetros estabelecidos pelo fabricante (sem valor mínimo a 0,21), na faixa etária estudada, com valores de 0,01 a 0,19.

Apesar da necessidade de múltiplas intervenções para a reabilitação da fissura labiopalatina ser um possível fator de estresse, especialmente devido à complexidade do tratamento, o HRAC não é um ambiente totalmente desconhecido para as crianças que o frequentam, justamente pelos constantes e inúmeros contatos com os profissionais de saúde, que possibilitam um atendimento diferenciando e humanizado em ambiente hospitalar. Isso poderia explicar a não ocorrência de níveis alterados de cortisol salivar, pois a realização do teste e coleta ocorreu dentro da normalidade dos atendimentos realizados rotineiramente no hospital. 
A diferença entre os resultados obtidos nesta pesquisa com os de Gomes et al. (2015) e Gomes et al. (2016), também pode estar pautada por diferenças ocorridas durante a análise da saliva. Os kits de análise são ultrassensíveis e detalhes como luminosidade e temperatura podem alterar 0 resultado final.

Outros autores (McCarthy et al. 2009, Curcio et al. 2013, Patil et al. 2015) também utilizaram a mesma unidade de medida deste trabalho $(\boldsymbol{\mu g} / \mathbf{d L})$ para mensurar o cortisol, mas utilizaram outro kit de ensaio, o que resulta em números completamente diferentes. Também foram encontradas outras unidades de medidas para cortisol salivar na literatura como o nmol/L (Kiess et al. 1995, Kirschbaum et al. 1996, Vedhara et al. 2000, Morelius et al. 2004, Rosmalen et al. 2005, Lindauer et al. 2006, Tornhage e Alfven 2006, Silva et al. 2007, Gassling et al. 2012), ng/mL (Qi et al. 2016, Nohara et al. 2016) e g/mL (Saliba et al. 2016). Além das pesquisas apresentarem unidades de medidas diferentes de cortisol, o que dificulta a comparação, cada fabricante tem uma padronização, com valores mínimos e máximos de cortisol que diferem consideravelmente.

Uma das hipóteses desta pesquisa era que 0 número de atendimentos no ambiente hospitalar, no dia em que fosse feita a coleta, pudesse ser, ao longo do dia, um fator estressor para as crianças do HRAC, aumentando seus níveis de cortisol. Entretanto, esta hipótese não se confirmou (Tabela 4). Na comparação geral, não houve correlação entre o número de atendimentos no dia com o nível de cortisol salivar obtido. Entretanto, evidenciou-se uma correlação positiva $(1,000 \mathrm{p} \leq 0,01)$ para o grupo de crianças com sete anos (Tabela 5). Provavelmente, o fato de o grupo ser formado por apenas três indivíduos explique tal achado, pois um dos indivíduos apresentou o maior nível de cortisol salivar desta pesquisa $(0,199 \mu \mathrm{g} / \mathrm{dL})$, valor que pode ter interferido na média do cortisol desse grupo como um todo.

\subsection{Teste de Habilidade de Atenção Auditiva Sustentada}

No presente estudo, a habilidade de atenção auditiva sustentada foi 
verificada pelo escore da pontuação total de erros (desatenção e impulsividade) e do decréscimo de vigilância, obtidos com a aplicação do THAAS em crianças com fissura labiopalatina, sem queixas auditivas ou de atenção e ausência de alteração auditiva no momento da avaliação.

Estudos têm evidenciado que, no THAAS, a idade tem maior influência do que a variável sexo (Hazin et al. 2012, Cortez et al. 2013, Rueda e Monteiro 2013, Coelho et al. 2014). Os resultados desta pesquisa se mostraram em concordância com isso, como pode se observar nos escores da pontuação total de erros (Tabela 6), quando a comparação é realizada entre as faixas etárias de seis, sete e oito, em relação às de nove, 10 e 11 anos. No entanto, as crianças de sete anos, deste trabalho, apresentaram piores resultados do que as crianças de seis anos, assim também se pode observar para as de 11 em relação às de 10 anos.

Vale ressaltar que, neste estudo, as crianças de sete anos, ao apresentarem um grande número de erros desatenção, contribuíram para o aumento do escore da pontuação total de erros, determinando a idade que apresentou o pior desempenho. Uma vez mais, chama-se atenção para o fato de que um pequeno número de crianças, apenas três, apresentavam esta idade, aspecto que pode colaborar para este achado. No entanto, o trabalho de Picolini et al. (2010), utilizando o mesmo instrumento para avaliar a atenção auditiva sustentada, em 50 crianças de sete anos de idade, sem fissura labiopalatina, concluiu que as crianças avaliadas no período da tarde e as que estudam em escolas públicas apresentaram pior desempenho na habilidade de atenção auditiva sustentada, evidenciando que o período do dia e o tipo de escola, pode ser uma possível fonte de variação na habilidade da criança, para sustentar a atenção auditiva. Seguindo a metodologia, o THAAS foi aplicado no período da tarde, porém, neste estudo, não se verificou se as crianças pertenciam a escolas públicas ou particulares. Saliente-se ainda que, somente para esta idade, semelhantemente aos observados por Lemos et al. (2010) e Picolini et al. (2010), o escore da pontuação total de erros, considerando um (1) desvio padrão, foi superior (pior) ao obtido no trabalho de Feniman et al. (2007b), que demonstrou o desempenho de crianças sem qualquer anomalia craniofacial, no THAAS, em cada faixa etária de seis a 11 anos, 
Lasee e Choi (2013) realizaram um trabalho com crianças de 5 a 9 anos, porém apresentaram seus resultados colapsados em uma só média. Os indivíduos apresentaram melhores médias para desatenção e impulsividade, em relação às crianças de 6 a 9 anos do presente trabalho. Possivelmente esta diferença deve-se à duração do teste: enquanto o teste utilizado por Lasee e Choi era composto de 180 palavras, pronunciadas uma a cada dois segundos, esta pesquisa utilizou o THAAS, que apresentou uma palavra por segundo, totalizando 600 palavras.

Quanto ao valor obtido, neste estudo, para o decréscimo de vigilância, o outro parâmetro considerado no desempenho do THAAS, as crianças mais velhas demonstraram um menor escore, porém, os valores se encontram dentro da normalidade (Feniman et al. 2007b) para todas as idades avaliadas, discordando de Lemos et al. (2010), que relataram que, para o decréscimo de vigilância, as crianças de sete anos, com fissura labiopalatina, apresentavam desempenho no THAAS inferior àquelas sem esta anomalia craniofacial.

Nesta pesquisa, apesar de os meninos apresentarem um comportamento mais desatento e impulsivo - apurados nos valores médios dos erros cometidos na aplicação do teste (Tabela 7), para a maioria das idades testadas - e as meninas mostrarem um melhor desempenho no THAAS, verificado pela pontuação total de erros, em quase todas as faixas etária estudadas, exceto para o grupo de seis e 11 anos, a diferença encontrada entre os sexos não foi significante (Tabela 8). Ausência de significância no desempenho no THAAS, entre os sexos, também foi relatada nos estudos de Lemos et al. (2010), Picolini et al. (2010) e Mondelli et al (2010). No que se refere à significância estatística, o mesmo foi observado em relação ao decréscimo de vigilância, ainda que seus valores médios tenham sido maiores para o sexo feminino na faixa etária dos seis aos nove anos.

Importante ressaltar que, das 69 crianças com fissura labiopalatina participantes deste estudo, considerando-se a pontuação total de erros e o decréscimo de vigilância no desempenho do teste proposto, apenas as crianças de 7 anos de idade demonstraram déficit na habilidade de atenção 
auditiva sustentada de acordo com a pontuação de desempenho proposta por Feniman et al. (2007b).

Esperava-se, contudo, um número maior de crianças com resultados piores no THAAS, uma vez que, na população com anomalias craniofaciais, especialmente nas com fissura labiopalatina, é notória a alta ocorrência de alterações de orelha média, com consequente perda auditiva condutiva. Estudos apontam que longos períodos de privação sensorial, na presença desse tipo de perda podem interferir na habilidade de atenção, no desenvolvimento das estruturas e funções do Sistema Nervoso Central (Andalibi et al. 2001, Dhooge et al. 2005, Piazentin-Penna e Jorge 2007). Além disso, no questionário realizado com os pais ou responsáveis pelas crianças deste estudo, quase $41 \%$ relataram a presença de otite média durante a primeira infância. Observe-se ainda, que uma pesquisa realizada por Lemos e Feniman (2010) demonstrou que o desempenho de crianças com fissura labiopalatina no THAAS era inferior ao de crianças sem esta malformação craniofacial e que elas também se encontravam na faixa etária de sete anos e apresentavam os mesmos tipos de fissura (transforame e pós-forame) do presente trabalho.

Nesta pesquisa, para o parâmetro pontuação total de erros no teste (Tabela 9), em quaisquer idades, não houve correlação significante entre 0 desempenho no THAAS e o nível de cortisol salivar. No entanto, observou-se uma correlação positiva $(1,000 \mathrm{p} \leq 0,01)$ para o decréscimo de vigilância nas crianças de sete anos, evidenciando-se que quanto mais alto o nível de cortisol salivar, mais as crianças declinaram sua atenção no decorrer do teste. Similar correlação foi encontrada entre o cortisol salivar e a desatenção, para as crianças de 11 anos de idade. Ressalte-se novamente, que o pequeno número de participantes nesta idade (três) pode ter contribuído para a correlação. O estudo de Vedhara et al. (2000), diferentemente, mostrou uma correlação negativa entre cortisol e desempenho cognitivo, comprovando-se melhores resultados em indivíduos sob condição de estresse. O mesmo ocorreu com 0 grupo de crianças de 9 anos desta pesquisa, que apresentou correlação negativa $(-528 \mathrm{p} \leq 0,05)$ entre o nível de cortisol salivar e a desatenção, demonstrada toda a vez que a criança não levantou a mão para a palavra-alvo 
"não". Existem muitas pesquisas que investigaram algumas causas do alto nível de cortisol após estímulos estressores (Kirschbaum et al. 1996, van Honk et al. 1998, Vedhara et al. 2000, Ellenbogen et al. 2002, Kalman e Grahn 2004, Lindauer et al. 2006, Roelofs et al. 2007, Jessop e Turner-Coob 2008, Henckens et al. 2012, Patil et al. 2015, Verdejo-Garcia et al. 2015, Qi et al. 2016, Nohara et al. 2016), observando que resultam em consequências negativas, que afetam as funções do cérebro - como a atenção e cognição, bem como o humor, causando irritação e perda de memória (Kirschbaum et al. 1996, van Honk et al. 1998, Kalman e Grahn 2004, Roelofs et al. 2007, Jessop e Turner-Coob 2008, Henckens et al. 2012, Patil et al. 2015, Verdejo-Garcia et al. 2015, Qi et al. 2016, Nohara et al. 2016).

O presente estudo apresenta algumas limitações. Novos trabalhos com uma amostra mais homogênea e maior número de indivíduos poderão trazer informações mais precisas sobre a correlação entre nível de cortisol e atenção auditiva sustentada. Pesquisas que contêm questionários para avaliação de ansiedade e dados de qualidade de vida podem contribuir com informações adicionais em relação ao estresse e ao aumento dos níveis de cortisol. Seria também interessante realizar um estudo sobre a possível influência do ambiente hospitalar em relação a ansiedade da criança, com coletas duplas, utilizando a própria criança como grupo controle, comparando-se as amostras realizadas em ambiente familiar ou de rotina com o ambiente hospitalar. 

7 Ponclusã̃o 



\section{CONCLUSÃo}

Foi possível verificar que houve correlação positiva entre o nível de cortisol salivar e a habilidade de atenção auditiva sustentada apenas nas crianças com fissura labiopalatina com sete anos de idade. 

Qeferências 



\section{REFERÊNCIAS}

Aardal R, Holm AC. Cortisol in saliva - reference ranges and relation to cortisol in sérum. Eur J Clin Chem Clin Biochem. 1995;33(12):927-32.

Abu-Samak M, Abu-Zaiton A, Al-Jaberi A, Sundookah A, Atrooz O, Abu-Khadra KM, Kuzaie R, Talib WH. Morning Salivary cortisol associates with elevated serum leptin levels in Jordanian young men with olive pollen induced allergic rhinitis. Br J Med Med Res. 2014;4(3):797-806.

Aires MM. Fisiologia. 3aㅗ ed. Rio de Janeiro: Guanabara Koogan; 2008.

Ali N, Pruessner JC. The salivary alpha amylase over cortisol ratio as a marker to assess dysregulations of the stress systems. Physiol Behav. 2012;106(1):6572.

Amenabar JN. Níveis de cortisol salivar, grau de estresse e de ansiedade em indivíduos com Síndrome de Ardência Bucal [tese]. Porto Alegre: Faculdade de Odontologia da Pontifícia Universidade Católica do Rio Grande do Sul; 2006.

Andalibi A, Li JD, Webster P, Lim DJ. Advances in treating middle ear infections in children. Hear Rev [online] 2001 Sept [consultado 23 nov. 2016]. Disponível: URL: http://www.hearingreview.com/2001/09/advances-in-treating-middle-earinfections-in-children.

Angerami VA. Tendência em Psicologia Hospitalar. São Paulo: Thompson Learning; 2004.

Antonini SR, Jorge SM, Moreira AC. The emergence of salivary cortisol circadian rhythm and its relationship to sleep activity in preterm infants. Clin Endocrinol. 2000;52(4):423-6.

Araújo AS, Moura JR, Camargo LA, Alves W. Avaliação auditiva em escolares. Rev Bras Otorrinolaringol. 2002;68(2):263-6. 
Belanoff JK, Gross K, Yager A, Schatzberg AF. Corticosteroids and cognition. J Psychiatr Res. 2001;35(3):127-45.

Burke PM, Reichler RJ. Smith E, Dugaw K, McCauley E, Mitchell J. Correlation between serum and salivary cortisol levels in depressed and non-depressed children and adolescents. Am J Psychiatry. 1985;142(9):1065-67.

Campos JF, David HMSL. Análise de cortisol salivar como biomarcador de stress ocupacional em trabalhadores de enfermagem. Rev enferm UERJ,. $2014 ; 22(4): 447-53$.

Carrion VG, Weems CF, Ray RD, Glaser B, Hessl D, Reiss A. Diurnal salivary cortisol in pediatric posttraumatic stress disorder. Biol Psychiatry. $2002 ; 1 ; 51(7): 575-82$.

Castro M, Elias PC, Quidute AR, Halah FP, Moreira AC. Outpatient screening for Cushing's syndrome: the sensitivity of the combination of circadian rhythm and overnight dexamethasone suppression salivary cortisol tests. J Clin Endocrinol Metab.1999;84(3):878-82.

Castro M, Moreira AC. Análise crítica do cortisol salivar na avaliação do eixo hipotálamo-hipófise-adrenal. Arq Bras Endocrinol Metab. 2003;47(4):358-67.

Chaves PC. Projeto brinquedoteca hospitalar "Nosso Cantinho": relato de experiência de brincar. In: Anais 7º Encontro de Extensão da UFMG; 2004. Belo Horizonte. Belo Horizonte: UFMG; 2004. Disponível: URL: http://www.ufmg.br/proex/arquivos/7Encontro/Saude150.pdf. Consultado em: 15 out. 2016

Chen Y-M, Cintron NM, Whitson PA. Long-term storage of salivary cortisol samples at room temperature. Clin Chem. 1992 Feb;38(2):304.

Chrousos GP. Stressors, stress, and neuroendocrine integration of the adaptive response. The 1997 Hans Selye Memorial Lecture. Ann N Y Acad Sci. 1998;851:311-35. 
Clements $A D$, Parker $C R$. The relationship between salivary cortisol concentrations in frozen versus mailed samples. Psychoneuroendocrinology. 1998;23(6):613-6.

Coelho DG, Lima RF, Ims RE, Fonseca GUS, Ciasca SM. Desempenho de estudantes em instrumentos de atenção e funções executivas: análise do efeito da idade. Revista Sul Americana de Psicologia. 2014;2(2):214-39.

Cortez R, Garcia DF, Maranhão S, Guerra A, Diniz NL, Falcão JTR, et al. O desenvolvimento dos mecanismos atencionais em estudantes brasileiros do ensino fundamental. Avances en Psicología Latinoamericana. 2013;31(1):16580.

Cosenza RM, Guerra LB. A lanterna na janela: a atenção e suas implicações na aprendizagem. In: Cosenza RM, Guerra LB. Neurociência e educação: como o cérebro aprende. Porto Alegre (RS): Artmed; 2011. p.41-50.

Curcio WB, Scalioni FAR, Soares MRPS, Devito KL, Chaves MGAM, Ribeiro RA. Salivary cortisol levels in children undergoing dental treatment - a pilot study. Pesq Bras Odontoped Clin Integr. 2013;13(1):5-10.

Cymrot M, Sales FCD, Teixeira FAA, Teixeira Junior FAA, Teixeira GSB, Cunha Filho JF et al. Prevalência dos tipos de fissura em pacientes com fissuras labiopalatina atendidos em um Hospital Pediátrico do Nordeste brasileiro. Rev Bras Cir Plást. 2010;25(4):648-51.

Darvann TA, Hermann NV, Ersboll BK, Kreiborg S, Berkowitz S. Palatal surface area of maxillary plaster casts - a comparison between two-dimensional and three-dimensional measurements. Cleft Palate Craniofac J. 2007;44(4):381-90.

Despopoulos A, Silbernagi S. Color Atlas of Physiology. New York; 2003.

Dhooge I, Desloovere C, Boudewyns A, Van Kempen M, Dachy JP. Management of otitis media with effusion in children. B-ENT. 2005;1(Suppl. 1):3-15. 
Ellenbogen MA, Schwartzman AE, Stewart J, Walker CD. Stress and selective attention: the interplay of mood, cortisol levels, and emotional information processing. Psychophysiology. 2002;39:723-32.

Feniman MR, Ortelan RR, Campos CF, Cruz MS, Lauris JRP. A habilidade de atenção auditiva sustentada em crianças. ACTA ORL/Técnicas em Otorrinol. 2007a;25(4):280-4.

Feniman MR, Ortelan RR, Lauris JRP, Campos CF, Cruz MS. Proposta de instrumento comportamental para avaliar a atenção auditiva sustentada. Rev Bras Otorrinolaringol. 2007b;73(4):523-7.

Feniman MR, Rissatto ACS, Lauris JRP, Mondelli MFCG. Aplicabilidade do teste da habilidade de atenção auditiva sustentada - THAAS em campo livre. Int Arch Otorhinolaryngol. 2012;16(2):269-77.

Ferreira AMA. Validação laboratorial do teste de cortisol salivar e índice cortisol/creatina na primeira urina da manhã no Hospital Santo António, Centro Hospitalar do Porto [dissertação]. Porto: Instituto de Ciências Biomédicas Abel Salazar; 2011.

Foley P, Kirschbaum C. Human hypothalamus-pituitary-adrenal axis responses to acute psychosocial stress in laboratory settings. Neurosci.Biobehav. 2010; 35(1):91-96.

Fries E, Dettenborn L, Kirschbaum C. The cortisol awakening response (CAR): facts and future directions. Int J Psychophysiol. 2009;72(1):67-73.

Gallagher P, Leitch MM, Massey AE, McAllister-Williams $\mathrm{RH}$, Young $\mathrm{AH}$. Assessing cortisol and dehydroepiandrosterone (DHEA) in saliva: effects of collection method. J. Psychopharmacol. 2006;20(5):643-9.

Garde AH, Hansen AM. Long-term stability of salivary cortisol. Scand J Clin Lab Invest. 2005;65(5)433-6. 
Garib DG, Silva Filho OG, Jason G, Pinto JHN. Etiologia das más oclusões: perspectiva clínica (parte III) - fissuras labiopalatina. Rev Clin Ortod Dental Press. 2010;9(4):30-6.

Gassling V, Holterhus PM, Herbers D, Kulle A, Niederberger U, Hedderich J, Wiltfang J, Gerber WD. Stress-coping and cortisol analysis in patients with nonsyndromic cleft lip and palate: an explorative study. Plos one. 2012;7(7):1-7.

Golden SH, Wand GS, Malhotra S, Kamel I, Horton K. Reliability of hypothalamic-pituitary-adrenal axis assessment methods for use in populationbased studies. Eur J Epidemiol. 2011;26(7):511-25.

Gomes HS, Corrêa-Faria P, Silva TA, Paiva SM, Costa PS, Batista AC, Costa LR. Oral midazolam reduces cortisol levels during local anaesthesia in children: a randomised controlled trial. Braz Oral Res. 2015;29(1):1-9.

Gomes HS, Vieira LA, Costa PS, Batista AC, Costa LR. Professional dental prophylaxis increases salivary cortisol in children with dental behavioural management problems: a longitudinal study. BMC Oral Health. 2016;16(1):74.

Gradin M, Eriksson M, Holmqvist G, Holstein A, Schollin J. Pain reduction at venipuncture in newborns: oral glucose compared with local anaesthetic cream. Pediatrics. 2002;110(6):1053-7.

Greenberg LM, Waldmant ID. Developmental normative data on The Test of Variables of Attention (TOVA ${ }^{\mathrm{TM}}$ ). Child PsydmI Piyditat. 1993;34(6):1019-30.

Groschl M, Wagner R, Rauh M, Dorr HG. Stability of salivary steroids: the influences of storage, food and dental care. Steroids. $2001 ; 66(10): 737-41$.

Groschl, M., Rauh, M., \& Dorr, H.G. Circadian rhythm of salivary cortisol, $17\{$ alpha\}-hydroxyprogesterone, and progesterone in healthy children. Clinical Chemistry. 2003;49(10):1688-91. 
Guechot J, Flet J, Passa P, Villette JM, Gourmel B, Tabuteau F et al.. Physiological and pathological variation in saliva cortisol. Horm Res. 1982;16(6):357-64.

Hanrahan K, McCarthy AM, Kleiber C, Lutgendorf S, Tsalikian E.

Strategies for salivary cortisol collection and analysis in research with children. Appl Nurs Res. 2006;19(2)95-101.

Hazin I, Falcão JTR, Garcia D, Gomes E, Cortez R, Maranhão S, et al. Dados normativos do Teste de Atenção por Cancelamento (TAC) em estudantes do ensino fundamental. Psico. 2012;43(4):428-36.

Hellhammer DH, Wüst S, Kudielka BM. Salivary cortisol as a biomarker in stress research. Psychoneuroendocrinology. 2009;34:163-71.

Henckens MJAG, van Wingen GA, Joels M, Fernández G. Time-dependent effects of cortisol on selective attention and emocional interference: a functional MRI study. Front Integr Neurosci. 2012;6(66):1-14.

Het S, Ramlow G, Wolf OT. A meta-analytic review of the effects of acute cortisol administration on human memory. Psychoneuroendocrinology. 2005;30(8):771-84.

Hiramatsu R. Direct assay of cortisol in human saliva by solid phase radioimmunoassay and its clinical applications. Clin Chim Acta. $1981 ; 117(2): 239-42$.

Jacobson L. Hypothalamic-Pituitary-Adrenocortical axis regulation. Endocrinol Metab Clin N Am. 2005;34(2)271-92.

Jerger J. Clinical experience with impedance audiometry. Arch Otolaryngol. 1970;92(4):311-24.

Jessop DS, Turner-Cobb JM. Measurement and meaning of salivary cortisol: a focus on health and disease in children. Stress. 2008;11(1)1-14. 
Kahn JP, Rubinow DR, Davis CL, Kling M, Post RM. Salivary cortisol: a practical method for evaluation of adrenal function. Biol. Psychiatry. 1988;23(4):335-49.

Kalman BA, Grahn RE. Measuring salivary cortisol in the behavioral neuroscience laboratory. J Undergrad Neurosci Educ. 2004;2(2)41-9.

Kanegane, K. Ansiedade ao tratamento odontológico de urgência e a sua relação com a dor e os níveis de cortisol salivar [dissertação]. São Paulo: Faculdade de Odontologia da Universidade de São Paulo; 2007.

Keller B. Estudo comparativo dos níveis de cortisol salivar e estresse em atleta de luta olímpica de alto rendimento [dissertação]. Curitiba: Universidade Federal do Paraná; 2006.

Kiess W, Meidert A, Dressendörfer RA, Schriever K, Kessler U, König A et al. Salivary cortisol levels throughout childhood and adolescence: relation with age, pubertal stage, and weight. Pediatr Res. 1995;37(4 Pt 1):502-6.

Kiess W, Pfaeffle R. Steroid analysis in saliva: a noninvasive tool for pediatric research and clinical practice. J Pediatr. 2007;83(2):97-9.

King SL, Hegadoren KM. Stress hormones: how do they measure up? Biol Res Nurs. 2002;4(2):92-103.

King JA, Rosal MC, Reed G, Kelly TA, Stanek EJI, Ockene IS. Sequence and seasonal effects of salivary cortisol. Behav Med. 2000;26(2):67-74.

Kirschbaum C, Hellhammer DH. Salivary cortisol in psychobiological research: an overview. Neuropsychobiology. 1989;22(3):150-69.

Kirschbaum C, Hellhammer DH. Salivary cortisol in psychoneuroendocrine research: recent developments and applications. Psychoneuroendocrinology. 1994;19(4):313-33. 
Kirschbaum C, Wolf OT, May M, Wippich W, Hellhammer DH. Stress and treatment induced elevations of cortisol levels associated with impaired declarative memory in healthy adults. Life Sciences. 1996;58(17)1475-83.

Klorman R, Brumaghim JT, Fitzpatrick PA, Borgstedt AD. Methylphenidate speeds evaluation processes of attention deficit disorder adolescents during a continuous performance test. J Abnorm Child Psychol. 1991;19(3):263-83.

Kudielka BM, Buske-Kirschbaum A, Hellhammer DH, Kirschbaum C. HPA axis responses to laboratory psychosocial stress in healthy elderly adults, younger adults, and children: impact of age and gender. Psychoneuroendocrinology. 2004;29(1):83-98.

Kudielka BM, Kirschbaum C. Awakening cortisol responses are influenced by health status and awakening time but not by menstrual cycle phase. Psychoneuroendocrinology. 2003;28(1):35-47.

Kudielka BM, Gierens A, Hellhammer DH, Wüst S, Schlotz W. Salivary cortisol in ambulatory assessment--some dos, some don'ts, and some open questions. Psychosom Med. 2012;74(4):418-31.

Lasee MJ, Choi H. Evidence of reliability and validity for a Children's Auditory Continuous Performance Test. SAGE Open. 2013;3:1-10.

Laudat MH, Cerdac S, Founirer C. Guiban D, Guilhaume B, Luton JP. Salivary cortisol measurement: a practical approach to assess pituitary-adrenal function. J Clin Endocrinol Metab. 1988;66(2):343-48.

Lemos ICC, Feniman MR. Sustained Auditory Attention Ability Test (SAAAT) in seven-year-old children with cleft lip and palate. Braz J Otorhinolaryngol. 2010;76(2):199-205.

Levav M , Mirsky AF , French LM, Bartko JJ. Multinational Neuropsychological Testing: performance of children and adults. J Clin Exp Neuropsychol. 1998;20(5):658-72. 
Lima MOPBS. Correlação entre o nível de cortisol salivar e o desempenho cognitivo em idosos sem déficit cognitivo [dissertação]. Belo Horizonte: Universidade Federal De Minas Gerais; 2014.

Lin $\mathrm{CCH}$, Hsiao CK, Chen WJ. Development of sustained attention assessed using the Continuous Performance Test among children 6-15 years of age. Journal of Abnormal Child Psychology. 1999;27(5):403-12.

Lindauer RJL, Olff M, van Meijel EPM, Carlier IVE, Gersons BPR. Cortisol, learning, memory, and attention in relation to smaller hippocampal volume in police officers with posttraumatic stress disorder. Biol Psychiatry. 2006;59(2):171-77.

Lipp MEN. O modelo quadrifásico do stress. In: Lipp MEN (Org.). Mecanismos neuropsicofisiológicos do stress: teoria e aplicações clínicas. São Paulo: Casa do Psicólogo; 2003. p.18-19.

Lo MSL, Ng ML, Azmy BS, Khalid BAK. Clinical applications of salivary cortisol measurements. Singap Med J 1992;33(2):170- 3.

Marques AH, Silverman MN, Sternberg EM. Evaluation of stress systems by applying noninvasive methodologies: measurements of neuroimmune biomarkers in the sweat, heart rate variability and salivary cortisol. Neuroimmunomodulation 2010;17(3):205-8.

Martinelli CE, Sader SL, Oliveira EB, Daneluzzi JC, Moreira AC. Salivary cortisol for screening of Cushing's syndrome in children. Clin Endocrinol 1999;51(1):67-71.

Maruyama Y, Kawano A, Okamoto S, Ando T, Ishitobi Y, Tanaka Y et al. Differences in salivary alpha-amylase and cortisol responsiveness following exposure to electrical stimulation versus the Trier Social Stress Tests. PLoS One. 2012;7(7):e39375. 
McCarthy AM, Hanrahan K, Kleiber C, Zimmerman MB, Lutgendorf S, Tsalikian E. Normative salivary cortisol values and responsivity in children. Appl Nurs Res. 2009;22(1):54-62.

Melgaço CA; Di Ninno CQMS, Penna LM, Vale MPP. Aspectos ortodônticos/ortopédicos e fonoaudiológicos relacionados a pacientes portadores de fissuras labiopalatina. J Bras Ortodon Ortop Facial 2002;7(37):23-32.

Miranda MC, Sinnes EG, Pompeia S, Bueno OFA. O K-CPT em uma amostra brasileira: descrição do desempenho e comparação com as normas norteamericanas. Rev Psiquiatr RS. 2009;31(1):60-66.

Mondelli MF, Carvalho FR, Feniman MR, Lauris JR. Mild hearing loss: performance in the Sustained Auditory Attention Ability Test. Pro Fono. 2010;22(3):245-50.

Morelius E, Nelson N, Theodorsson E. Salivary cortisol and administration of concentrated oral glucose in newborn infants: improved detection limit and smaller sample volumes without glucose interference. Scand J Clin Lab Invest. 2004;64(2):113-8.

Nederhof E, van Oort FVA, Bouma EMC, Laceulle OM, Oldehinkel AJ, Ormel J. Predicting mental disorders from hypothalamic-pituitary-adrenal axis functioning: a 3-year follow-up in the TRAILS study. Psychol Med. 2015;45(11):2403-12.

Nieman LK, Biller BMK, Findling JW, Newell-Price J, Montori VM. The diagnosis of Cushing's syndrome: an Endocrine Society Clinical Practice Guideline. J. Clin. Endocrin. \& Metabol. 2008:93(5):1526-40.

Nohara M, Tohei A, Sato T, Amao H. Evaluation of response to restraint stress by salivary corticosterone levels in adult male mice. $J$ Vet Med Sci. 2016;78(5):775-80. 
Noordhoff MS. Establishing a craniofacial center in a developing country. $J$ Craniofac Surg 2009;20(2):1655-6.

Novais M E, Frota MS. Tratamento médico do stress. In: Lipp MEN (Org.). Mecanismos neuropsicofisiológicos do stress: teoria e aplicações clínicas. São Paulo: Casa do Psicólogo; 2003. p.177.

Patil SJ, Shah PP, Patil JA, Shigli A, Patil AT, Tamagond SB. Assessment of the changes in the stress-related salivary cortisol levels to the various dental procedures in children. J. Indian Soc. Pedod. Prev. Dent. 2015;33(2):94-9.

Piazentin-Penna SHA, Jorge JC. Avaliação e tratamento dos distúrbios da audição. In: Trindade IEK, Silva Filho OG. Fissuras Labiopalatinas: umas abordagem interdisciplinar. São Paulo: Santos; 2007. p.165-172.

Picolini MM, Stivanin D, Sampaio AR, Salvador KK, Lauris JRP, Feniman MR, et al. Auditory attention: time of day and type of school. Int Arch Otorhinolaryngol. 2010;14(2):174-9.

Qi M, Gao H, Guan L, Liu G, Yang J. Subjective stress, salivary cortisol, and electrophysiological responses to psychological stress. Front Psychol. 2016;7:229.

Raff H. Salivary cortisol: a useful measurement in the diagnosis of Cushing's syndrome and the evaluation of the hypothalamic-pituitary-adrenal axis. The Endocrinologist 2000;10:9-17.

Reddy SG, Reddy LV, Reddy RR. Developing and standardizing a center to treat cleft and craniofacial anomalies in a developing country like India. $J$ Craniofac Surg 2009;20(Suppl 2):1664-7.

Riad-Fahmy D, Read GF, Walker RF, Griffiths K. Steroids in saliva for assessing endocrine function. Endocrine Rev. 1982;3:367-95.

Richards JE. The development of sustained attention in infants. In: Posner MI. Cognitive neuroscience of attention. New York: Guilford Press; 2004. p.342-56. 
Roelofs K, Bakvis P, Hermans EJ, van Pelt J, van Honk J. The effects of social stress and cortisol responses on the preconscious selective attention to social threat. Biol Psychiatry. 2007;75(1):1-7.

Rohleder N, Beulen SE, Chen E, Wolf JM, Kirschbaum C. Stress on the dance floor: the cortisol stress response to social-evaluative threat in competitive ballroom dancers. Pers Soc Psychol Bull. 33(1):69-84.

Rosmalen JG, Oldehinkel AJ, Ormel J, Winter AF, Buitelaar JK, Verhulst FC. Determinants of salivary cortisol levels in 10-12 year old children; a population based study of individual differences. Psychoneuroendocrinology. 2005;30(5):483-95.

Rueda FJM, Monteiro RMM. Bateria psicológica para avaliação da atenção (BPA): desempenho de diferentes faixas etárias. Psico-USF. 2013;18(1):99108.

Saliba FG, Adiwardana NS, Uehara EU, Silvestre RN, Leite VV, Faleiros FT, Padovani FH et al. Salivary cortisol levels: the importance of clown doctors to reduce stress. Pediatr Rep. 2016;31;8(1):6188.

Salimetrics. Expanded range high sensitivity salivary cortisol enzyme immunoassay kit. @ Salimetrics, Inc. [online]. [consultado em 12 ago. 2016]. Disponível: URL: https://www.salimetrics.com/assets/documents/1-3002n.pdf.

Santiago LB, Jorge SM, Moreira AC. Longitudinal evaluation of the development of salivary cortisol circadian rhythm in infancy. Clin Endocrinol 1996;44:157-61.

Sapolsky RM, Romero LM, Munck AU. How do glucocorticoids influence stress responses? Integrating permissive, suppressive, stimulatory, and preparative actions. Endocr Rev. 2000;21(1):55-89.

Sarsted. Salivette $\AA$ - Higienic saliva collection for diagnostics and monitoring. Nümbrecht, Germany: Sarsted; 2005. 
Scheer FA, Buijs RM. Light affects morning salivary cortisol in humans. J Clin Endocrinol Metab. 1999;84(9):3395-8.

Schlotz W, Hellhammer J, Schulz P, Stone AA. Perceived work overload and chronic worrying predict weekend-weekday differences in the cortisol awakening response. Psychosom Med. 2004;66(2):207-14.

Schmidt, NA. Salivary cortisol testing in children. Issues in comprehensive pediatric nursing. 1997;20(3):183-90.

Semb G. Brattstrom V, Molsted K, Prahl-Andersen B, Shaw WC. The Eurocleft study: intercenter study of treatment outcome in patients with complete cleft lip and palate. Part 1: Introduction and treatment experience. Cleft Palate Craniofac J. 2005;42:64-68.

Shimada, M, Takahashi, K, Ohkawa, T, Segawa, M, Higurashi, M. Determination of salivary cortisol by ELISA and its application to the assessment of the circadian rhythm in children. Horm. Res. 1995;44(5):213-7.

Silva Filho OG, Freitas JAS. Caracterização morfológica e origem embriológica. In: Trindade IEK, Silva Filho OG. Fissuras labiopalatais: uma abordagem interdisciplinar. São Paulo: Santos; 2007. p.17-49.

Silva ML, Mallozi MC, Ferrari GF. Salivary cortisol to assess the hypothalamicpituitary-adrenal axis in healthy children under 3 years old. J Pediatr. 2007;83(2):121-6.

Skogsdahl Y, Eriksson M, Schollin J. Analgesia in newborns given oral glucose. Acta Paediatr. 1996;86(2):217-20.

Spina V, Psillakis JM, Lapa FS. Classificação das fissuras lábio-palatinas: sugestão de modificação. Rev Hosp Clin Fac Med São Paulo 1972;27:5-6.

Takai N, Yamaguchi M, Aragaki T, Eto K, Uchihashi K, Nishikawa Y. Effect of psychological stress on the salivary cortisol and amylase levels in healthy young adults. Arch Oral Biol 2004;49(12):963-8. 
Thorn L, Hucklebridge F, Esgate A, Evans P, Clow A. The effect of dawn simulation on the cortisol response to awakening in healthy participants. Psychoneuroendocrinology. 2004;29(7):925-30.

Tornhage CJ. Reference values for morning salivary cortisol concentrations in healthy school-aged Children.J Pediatr Endocrinol Metab. 2002;15(2):197-204.

Tornhage CJ, Alfven G. Diurnal salivary cortisol concentration in school-aged children: increased morning cortisol concentration and total cortisol concentration negatively correlated to body mass index in children with recurrent abdominal pain of psychosomatic origin. $J$ Pediatr Endocrinol Metab. 2006;19(6):843-54.

Trindade IEK, Silva Filho OG. Fissuras Labiopalatinas: uma abordagem interdisciplinar. São Paulo: Santos; 2007.

Umeda T, Hiramatsu R, Iwaoka T, Shimada T, Miura F, Sato T. Use of saliva for monitoring unbound free cortisol levels in serum. Clin Chim Acta 1981;110(23):245-53.

Van Cauter E. Diurnal and ultradian rhythms in human endocrine function: a minireview. Horm Res 1990;34(2):45-53.

Van Honk J, Tuiten A, van den Hout M, Koppeschaar H, Thijssen J, Haan E, Verbaten R. Baseline salivary cortisol levels and preconscious selective attention for threat. Psychoneuroendocrinology. 1998;23(7)741-47.

Vargervik K, Oberoi S, Hoffman WY. Team care for the patient with cleft: UCSF protocols and outcomes. J Craniofac Surg 2009;20(Suppl 2):1668-71.

Vedhara K, Hyde J, Gilchrist ID, Tytherleigh M, Plummer S. Acute stress, memory, attention and cortisol. Psychoneuroendocrinology. 2000;5:535-49.

Verdejo-Garcia A, Moreno-Padilla M, Garcia-Rios MC, Lopez-Torrecillas F, Delgado-Rico E, Schmidt-Rio-Valle $\mathrm{J}$ et al. Social stress increases cortisol and 
hampers attention in adolescents with excess weight. PLoS One. 2015;10(4):112.

Vining RF, McGinley RA. The measurement of hormones in saliva: possibilities and pitfalls. J Steroid Biochem 1987;27(1-3):81-94.

Wang G, Yang Y, Wang K, Wu Y, Tao J, Xu H, et al. Current status of cleft lip and palate management in China. J Craniofac Surg 2009; 20(Suppl 2):1637-9.

WHO. World Health Organization. Global strategies to reduce the health-care burden of craniofacial anomalies. Genebra: WHO; 2002.

Woolston JL, Gianfredi S, Gertner JM, Paugus JA, Mason JW. Salivary cortisol: a nontraumatic sampling technique for assaying cortisol dynamics. J Am Acad Child Psychiatry. 1983;22(5):474-6.

Wust S, Federenko I, Hellhammer DH, Kirschbaum C. Genetic factors, perceived chronic stress, and the free cortisol response to awakening. Psychoneuroendocrinology. 2000a;25(7):707-20.

Wust S, Wolf J, Hellhammer DH, Federenko I, Schommer N, Kirschbaum C. The cortisol awakening response normal values and confounds. Noise Health. 2000b;2(7):79-88. 

Aneseos 

Anexo A - QuestionÁRIO/ AudiçÃo-ATEnçÃo

\section{Parte I - IDENTIFICAÇÃO DO PARTICIPANTE}

Nome:

Gênero: Data de nascimento: Idade:

Grau de escolaridade:

\section{Parte II - SAÚDE AUDITIVA}

História de perda auditiva. Orelha afetada: $\quad$ ( )OD ( )OE História de infecções de "ouvido". Qual orelha? Quantas vezes?

\section{Parte III - ATENÇÃO DO PARTICIPANTE}

( ) Não presta atenção às instruções $50 \%$ ou mais vezes

( ) Necessita frequentemente que as instruções sejam repetidas

( ) Diz "an?" e "o quê?" várias vezes ao dia

( ) Não pode prestar atenção ao estímulo auditivo por mais que pouco segundos

( ) Apresenta atenção curta

( ) Sonha acordado

( ) É facilmente distraído pelo ruído de fundo

( ) Apresenta transtorno de déficit de atenção e hiperatividade (TDAH)

( ) Toma medicamento para TDAH

\section{Parte IV - DADOS ESCOLARES}

( ) Repetência Quantas vezes?

( ) Professora tem queixa de desatenção

( ) Apresenta problemas de comportamento 



\section{ANEXO B - PROTOCOLO THAAS}

\section{THAPS Teste de Habilidade de Atenção Auditiva Sustentada}

Nome:

D.N.

Escolaridade: Data: Avaliador:

Treino

1 céu

2 pai

3 n

4 flo

5 sol

6 กล̃ก

7 boi

8 quer

9 gás

10 กลัก

11 meu

12 sim

13 pé

$14 \mathrm{mal}$

$15 \mathrm{gol}$

16 não

17 trem

18 这

19 mar

20 กล่̃

\begin{tabular}{l|l|l}
21 & vou \\
22 & já
\end{tabular}

23 pó

24 sal

25 um

26 céu

\begin{tabular}{l|l|}
27 & pai \\
28 & não \\
&
\end{tabular}

29 filor

30 sol

31 não

32 boi

33 quer

34 gás

35 năo

36 meu

37 sim

38 pé

$39 \mathrm{ma}$

40 gol

41 năo

42 trem

43 Iã

44 mar

\begin{tabular}{l|l|l|}
45 & não \\
\cline { 2 - 3 } 46 & พพัน
\end{tabular}

47 já

48 pó

\begin{tabular}{l|l|l|}
49 & sal & \\
\cline { 2 - 3 } 50 & um &
\end{tabular}

Análise de erros:
Apresentação

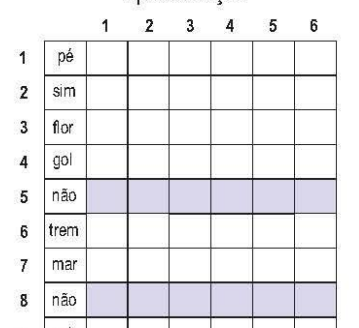

9 so

10 qu

$11 \mathrm{ma}$

12 la

14 meu

15 กล̃o

16 Sal

18 gas

19 vou

20 céu

21 nã̃o

22 já

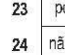

25 um

26 lã

\begin{tabular}{l|l|}
27 & boi \\
28 & sal \\
\cline { 2 - 2 } &
\end{tabular}

29 não

\begin{tabular}{l|l}
29 & nào \\
30 & mal \\
3 &
\end{tabular}

31 mar

32 gol

33 já

34 não

\begin{tabular}{l|l|}
35 & sim \\
\cline { 2 - 2 } 36 & gás \\
\end{tabular}

37 you

38 céu

39 nâ

41 trem

42 กล̃

43 flor

44 sol

45 não

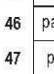

48 me

\begin{tabular}{l|l|}
49 & Po \\
\cline { 3 - 3 } 50 & um \\
\end{tabular}

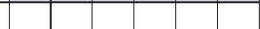

a

meu

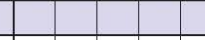

ai

\begin{tabular}{lll|l|l|l}
\hline & & & & & \\
\hline
\end{tabular}

\begin{tabular}{lll} 
& \\
\hline & &
\end{tabular}

o

boi

0

mar

\begin{tabular}{|l|l|}
\hline já & \\
\hline não & \\
\hline
\end{tabular}

an

\begin{tabular}{ll}
$x_{1}$ \\
\hline
\end{tabular}

quer

\begin{tabular}{|l|l|l|}
\hline กồ & \\
\hline for &
\end{tabular}

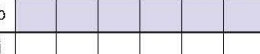

\begin{tabular}{|l|l|l|l|l|l|}
\hline pen & & & & & \\
\hline
\end{tabular}

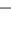

Resp. corretas na $1^{\text {a }}$ apres

Desatenção:

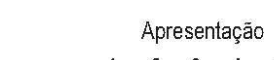

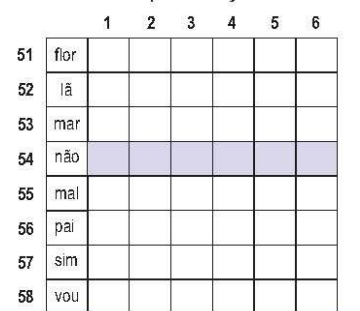

59 nà

60 pé

$61 \mathrm{~m}$

62 boi

$64 \mathrm{gol}$

65 tren

66 quer

68 sol

70 gás

71 กล̃o

72 sal

73 Pó

74 céu

\begin{tabular}{l|l}
75 & um \\
\cline { 3 - 3 } 76 & lã
\end{tabular}

77 mar

78 sal

\begin{tabular}{l|l|}
79 & nã̃o \\
\cline { 2 - 2 } 80 & flor
\end{tabular}

81 que

82 กล̃o

\begin{tabular}{l|l|}
83 & gás \\
\cline { 2 - 2 } 84 & sim
\end{tabular}

85 mal

86 vou

87 meu

88 já

\begin{tabular}{l|l|}
89 & não \\
\cline { 2 - 2 } 90 & pai
\end{tabular}

91 nà

92 pó

93 trem

94 pé

95 gol

96 so

97 กล̃o

$99 \mathrm{cel}$

$100 \mathrm{um}$

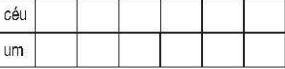

-

Impulsividade: 

Apênatice 

ApÊNDICE A - RESULTAdo GERAL

\begin{tabular}{|c|c|c|c|c|c|c|c|c|c|}
\hline Paciente & $\begin{array}{l}\text { Pont. } \\
\text { Total }\end{array}$ & $\begin{array}{l}\text { Decr. vi- } \\
\text { gilância }\end{array}$ & $\begin{array}{l}\text { Desaten- } \\
\text { ção }\end{array}$ & $\begin{array}{l}\text { Impulsivi } \\
\text { dade }\end{array}$ & Cortisol & $\begin{array}{c}\mathrm{N} . \\
\text { atendi- } \\
\text { mentos }\end{array}$ & Sexo & $\begin{array}{l}\text { Ida- } \\
\text { de }\end{array}$ & Tipo fissura \\
\hline 1 & 7 & 2 & 2 & 5 & 0,042154997 & 2 & $\bar{M}$ & 10 & Transforame \\
\hline 2 & 2 & 0 & 1 & 1 & 0,041003839 & 4 & $\mathrm{~F}$ & 8 & Pós-forame \\
\hline 3 & 3 & 1 & 3 & 0 & 0,080295855 & 3 & $\mathrm{~F}$ & 10 & Transforame \\
\hline 4 & 21 & 2 & 16 & 5 & 0,703040843 & 2 & $M$ & 8 & Transforame \\
\hline 5 & 22 & 6 & 19 & 3 & 0,143617932 & 3 & $\mathrm{~F}$ & 8 & Transforame \\
\hline 6 & 5 & 1 & 2 & 3 & 0,032364528 & 6 & $M$ & 8 & Transforame \\
\hline 7 & 15 & 0 & 7 & 8 & 0,022752523 & 2 & M & 10 & Transforame \\
\hline 8 & 4 & -1 & 4 & 0 & 0,035434177 & 4 & M & 10 & Pré + Pós \\
\hline 9 & 27 & 0 & 11 & 16 & 0,034991023 & 2 & $\mathrm{M}$ & 6 & Transforame \\
\hline 10 & 6 & 0 & 4 & 2 & 0,025609858 & 4 & $\mathrm{~F}$ & 10 & Transforame \\
\hline 11 & 10 & 2 & 4 & 6 & 0,024352545 & 5 & $\mathrm{~F}$ & 10 & Transforame \\
\hline 12 & 28 & 1 & 15 & 13 & 0,021472732 & 2 & $M$ & 8 & Transforame \\
\hline 14 & 21 & 3 & 20 & 1 & 0,027688188 & 4 & $\mathrm{~F}$ & 10 & Transforame \\
\hline 15 & 5 & 0 & 2 & 3 & 0,038117414 & 4 & $M$ & 10 & Transforame \\
\hline 16 & 50 & -1 & 47 & 3 & 0,025934201 & 3 & M & 7 & Transforame \\
\hline 17 & 23 & 4 & 19 & 4 & 0,199212682 & 5 & $\mathrm{~F}$ & 7 & Transforame \\
\hline 18 & 21 & 2 & 11 & 10 & 0,048903999 & 3 & $M$ & 6 & Pós-forame \\
\hline 19 & 1 & 0 & 0 & 1 & 0,031480725 & 2 & $\mathrm{~F}$ & 10 & Pós-forame \\
\hline 20 & 13 & 1 & 9 & 4 & 0,028898675 & 4 & $M$ & 7 & Pré + Pós \\
\hline 21 & 25 & 4 & 20 & 5 & 0,041943318 & 2 & $M$ & 8 & Transforame \\
\hline 22 & 8 & 0 & 4 & 4 & 0,041003839 & 4 & $M$ & 10 & Transforame \\
\hline 23 & 13 & 2 & 10 & 3 & 0,036154926 & 2 & M & 9 & Pré + Pós \\
\hline 24 & 16 & 3 & 13 & 3 & 0,042474521 & 6 & M & 8 & Transforame \\
\hline 25 & 9 & 0 & 1 & 8 & 0,034293477 & 3 & $\mathrm{~F}$ & 6 & Transforame \\
\hline 26 & 10 & 0 & 6 & 4 & 0,154493337 & 1 & $\mathrm{~F}$ & 9 & Transforame \\
\hline 27 & 12 & 1 & 6 & 6 & 0,027341909 & 4 & $M$ & 6 & Transforame \\
\hline 28 & 11 & 1 & 3 & 8 & 0,022467971 & 3 & $\mathrm{M}$ & 6 & Transforame \\
\hline 29 & 0 & 0 & 0 & 0 & 0,020521579 & 1 & $\mathrm{~F}$ & 10 & Transforame \\
\hline 30 & 37 & 7 & 30 & 7 & 0,024475447 & 6 & M & 10 & Pré + Pós \\
\hline 31 & 35 & 5 & 34 & 1 & 0,028537257 & 3 & $\mathrm{~F}$ & 6 & Transforame \\
\hline 32 & 34 & 3 & 30 & 4 & 0,023747229 & 6 & $M$ & 6 & Transforame \\
\hline 33 & 8 & 1 & 5 & 3 & 0,023987529 & 3 & $\mathrm{~F}$ & 6 & Transforame \\
\hline 34 & 7 & -1 & 6 & 1 & 0,032283167 & 6 & $\mathrm{~F}$ & 10 & Pré + Pós \\
\hline 35 & 7 & 0 & 3 & 4 & 0,029264671 & 2 & $M$ & 11 & Transforame \\
\hline 36 & 4 & -2 & 3 & 1 & 0,049773292 & 5 & $\mathrm{M}$ & 9 & Transforame \\
\hline 37 & 19 & 4 & 15 & 4 & 0,033356999 & 4 & $\mathrm{~F}$ & 9 & Transforame \\
\hline 38 & 4 & 0 & 2 & 2 & 0,096492245 & 2 & $M$ & 9 & Transforame \\
\hline 39 & 3 & 1 & 2 & 1 & 0,05408415 & 4 & $\mathrm{M}$ & 10 & Pré + Pós \\
\hline 40 & 17 & 2 & 13 & 4 & 0,022298951 & 4 & $\mathrm{~F}$ & 9 & Transforame \\
\hline 41 & 5 & 0 & 0 & 5 & 0,120417279 & 3 & $M$ & 10 & Transforame \\
\hline 42 & 13 & 3 & 8 & 5 & 0,024723116 & 4 & $\mathrm{~F}$ & 6 & Pré + Pós \\
\hline 43 & 7 & 1 & 2 & 5 & 0,024537131 & 5 & $M$ & 11 & Pré + Pós \\
\hline 44 & 21 & 1 & 12 & 9 & 0,033106063 & 4 & $\mathbf{F}$ & 11 & Transforame \\
\hline 45 & 0 & 0 & 0 & 0 & 0,03179928 & 6 & $\mathrm{~F}$ & 9 & Transforame \\
\hline 46 & 12 & 4 & 10 & 2 & 0,064180573 & 2 & $\mathrm{~F}$ & 8 & Pós-forame \\
\hline 47 & 14 & 1 & 10 & 4 & 0,08813316 & 4 & $M$ & 8 & Transforame \\
\hline 48 & 11 & 0 & 8 & 3 & 0,035434177 & 3 & $\mathrm{M}$ & 8 & Pré + Pós \\
\hline 49 & 8 & 0 & 2 & 6 & 0,036337392 & 5 & $\mathrm{~F}$ & 8 & Pós-forame \\
\hline 50 & 11 & -1 & 9 & 2 & 0,032609842 & 3 & $\mathrm{~F}$ & 9 & Pós-forame \\
\hline 51 & 9 & 1 & 9 & 0 & 0,050913697 & 4 & $\mathrm{~F}$ & 10 & Transforame \\
\hline 52 & 16 & -2 & 9 & 7 & 0,035345099 & 1 & $\mathrm{~F}$ & 10 & Transforame \\
\hline 53 & 5 & 1 & 4 & 1 & 0,103277856 & 3 & $\mathrm{~F}$ & 10 & Transforame \\
\hline 54 & 18 & 3 & 16 & 2 & 0,069915003 & 4 & $\mathrm{~F}$ & 6 & Pós-forame \\
\hline 55 & 36 & 5 & 33 & 3 & 0,033106063 & 2 & M & 9 & Transforame \\
\hline 56 & 8 & 0 & 2 & 6 & 0,045576024 & 4 & $\mathrm{~F}$ & 10 & Transforame \\
\hline 57 & 7 & 1 & 1 & 6 & 0,084654312 & 5 & $M$ & 9 & Pré + Pós \\
\hline 58 & 12 & 3 & 9 & 3 & 0,028898675 & 2 & $\mathrm{~F}$ & 9 & Transforame \\
\hline 59 & 12 & -1 & 7 & 5 & 0,047329678 & 4 & $\mathrm{~F}$ & 10 & Transforame \\
\hline 60 & 21 & 1 & 7 & 14 & 0,139344868 & 3 & $M$ & 8 & Pré + Pós \\
\hline 61 & 27 & 3 & 18 & 9 & 0,081108373 & 4 & $M$ & 6 & Transforame \\
\hline 62 & 13 & 2 & 8 & 5 & 0,052872731 & 4 & $M$ & 10 & Transforame \\
\hline 63 & 14 & 2 & 13 & 1 & 0,079691813 & 2 & M & 10 & Transforame \\
\hline 64 & 38 & 4 & 20 & 18 & 0,050913697 & 5 & $\mathbf{M}$ & 8 & Transforame \\
\hline 65 & 3 & 0 & 1 & 2 & 0,049274679 & 2 & $M$ & 8 & Pré + Pós \\
\hline 66 & 23 & 0 & 17 & 6 & 0,015676341 & 3 & $M$ & 9 & Transforame \\
\hline 67 & 9 & 0 & 1 & 8 & 0,132837686 & 4 & $M$ & 9 & Pré + Pós \\
\hline 68 & 7 & -1 & 3 & 4 & 0,053273492 & 3 & $\mathrm{M}$ & 9 & Transforame \\
\hline 69 & 27 & 0 & 24 & 3 & 0,176986182 & 4 & $\mathrm{M}$ & 6 & Transforame \\
\hline 70 & 48 & 6 & 41 & 7 & 0,038213478 & 3 & $\mathrm{~F}$ & 6 & Transforame \\
\hline 71 & 19 & 0 & 11 & 8 & 0,032692026 & 4 & $\mathrm{~F}$ & 9 & Transforame \\
\hline
\end{tabular}

